\title{
LLNL Inductrack Progress Report - February 99 through November 99
}

\author{
T. Louann
}

March 8, 2000

U.S. Department of Energy

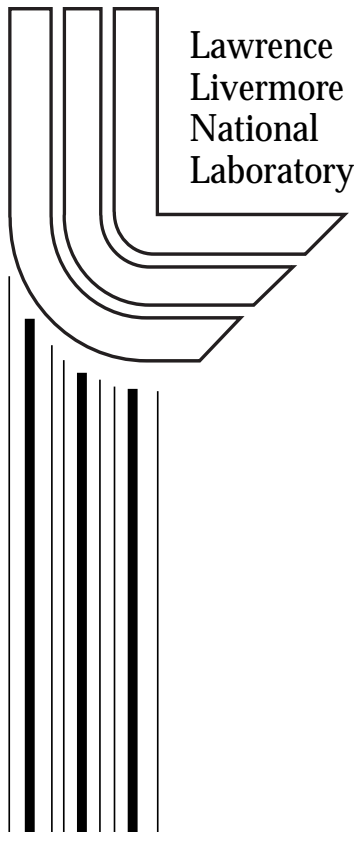




\section{DISCLAIMER}

This document was prepared as an account of work sponsored by an agency of the United States Government. Neither the United States Government nor the University of California nor any of their employees, makes any warranty, express or implied, or assumes any legal liability or responsibility for the accuracy, completeness, or usefulness of any information, apparatus, product, or process disclosed, or represents that its use would not infringe privately owned rights. Reference herein to any specific commercial product, process, or service by trade name, trademark, manufacturer, or otherwise, does not necessarily constitute or imply its endorsement, recommendation, or favoring by the United States Government or the University of California. The views and opinions of authors expressed herein do not necessarily state or reflect those of the United States Government or the University of California, and shall not be used for advertising or product endorsement purposes.

This work was performed under the auspices of the U. S. Department of Energy by the University of California, Lawrence Livermore National Laboratory under Contract No. W-7405-Eng-48.

This report has been reproduced directly from the best available copy.

Available electronically at http://www.doe.gov/bridge

Available for a processing fee to U.S. Department of Energy

and its contractors in paper from

U.S. Department of Energy

Office of Scientific and Technical Information

P.O. Box 62

Oak Ridge, TN 37831-0062

Telephone: (865) 576-8401

Facsimile: (865) 576-5728

E-mail: reports@adonis.osti.gov

Available for the sale to the public from

U.S. Department of Commerce

National Technical Information Service

5285 Port Royal Road

Springfield, VA 22161

Telephone: (800) 553-6847

Facsimile: (703) 605-6900

E-mail: orders@ntis.fedworld.gov

Online ordering: http://www.ntis.gov/ordering.htm

OR

Lawrence Livermore National Laboratory

Technical Information Department's Digital Library

http://www.llnl.gov/tid/Library.html 


\section{LLNL Inductrack Progress Report - period: February 1999}

Financial: Expenditures in February were approximately $\$ 38.6 \mathrm{~K}$. This estimate includes the $\$ 4 \mathrm{~K}$ overrun from last year's effort on Inductrack and the 3\% DOE Laboratory use tax charged to all Federal Agencies. An exact invoice will be forwarded to NASA about the $15^{\text {th }}$ of the month by the LLNL Finance Department.

\section{Accomplishments:}

General: $\quad$ On February $1^{\text {st }}$ an Inductrack team meeting was held to assess our goals and determine issues that needed attention to restart the project. The following assignments of responsibility were made:

Lead scientist:

Lead engineer:

Project engineer:

Capacitor bank design:

Track design and fab and experiment operator:

Launch cradle design

and dynamic analysis:

Launch cradle fab:

Aerodynamics: students)
Dick Post

Ray Smith

Tony Ladran (work schedule being reviewed)

Ed Cook

Bill Kent

Joel Martinez-Frias

Nick Patz (Engineering summer student)

Penn State (Professor George Dulikravich and

On 16 February, Dick Post, Ed Cook and Ray Smith participated in a conference call with MSFC focusing on the resonant drive circuitry and capacitor bank design. Program Manager Sherry Bushman offered to make arrangements for funding the February to February contract instead of February to September 30, 1999. We are preparing a spending plan for the February to February duration in order to estimate the spending in FY99 and in FY00.

Launch cradle: Modifications and improvements in the design of the model launch cradle and its magnet configuration were initiated. It was decided to employ magnet bars fabricated to required specifications, rather than attempt to fit the design to stock magnet sizes. In this way it will be possible to better optimize the weight of the assembly and its levitating capabilities while reducing the handling difficulty of a large number of magnets. This also lowers the cost of the Halbach array magnet assemblies. Aluminum containers for Halbach array units have been designed to allow levitation spacing from 8 to $12 \mathrm{~mm}$. (This is the distance between the array and the track.) Definition of general dimensions of the magnetic array, cart, and track are complete. Shown in the figure below is a simulation of the magnetic field of the new Halbach array design. 


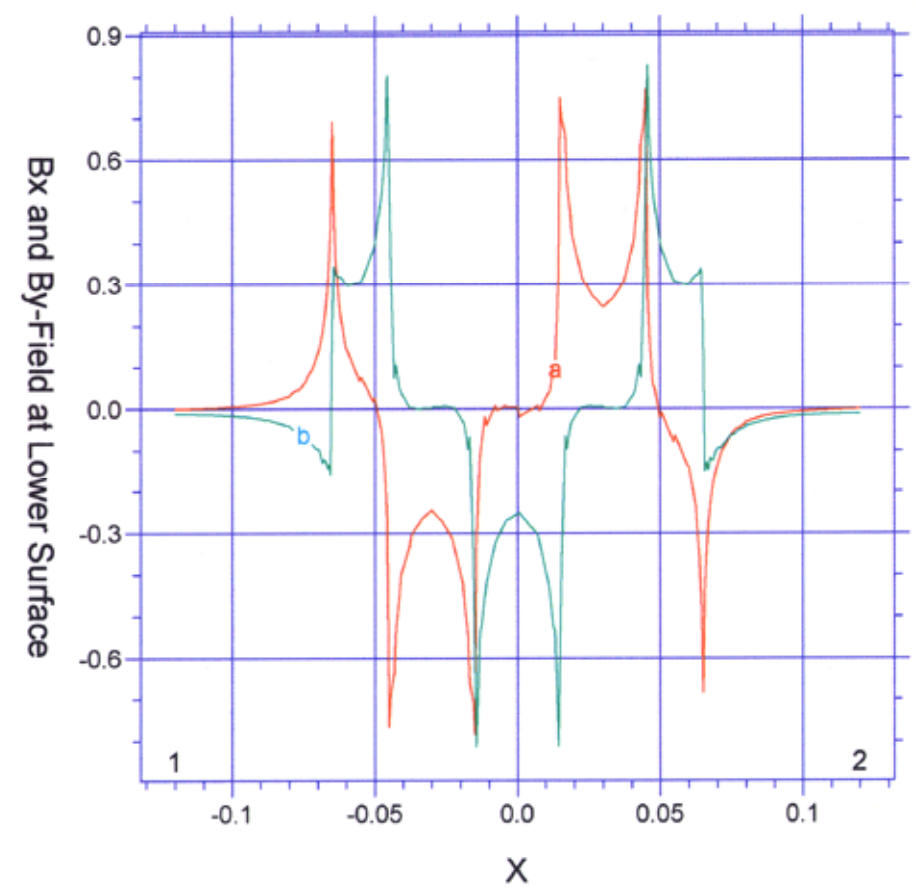

ELEVATION

From $(-0.12,-5.0 \mathrm{e}-3)$

To $(0.12,-5.0 \mathrm{e}-3)$

a: $d y(A z)$

b: $-d x(A z)$

MAGLEV_ARRAY: Grid\#6 p2 3953 Nodes 1954 Cells RMS Err= 4.1e-5

Integral $(a)=-6.873134 \mathrm{e}-5$ Integral $(\mathrm{b})=-1.820021 \mathrm{e}-5$

This simulation depicts the vertical (curve a) and horizontal (curve b) magnetic fields below the new launch cradle Halbach array. The "x direction" is along the length of the array and cradle.

Track: Studies of alternative designs for the track coil modules were initiated to optimizing their electrical properties, at the same time looking toward reducing their cost. We are examining the eddy current loses associated with using solid copper wire windings instead of the Litz wire we have used for coils.

The track will be located in Building 435 which has a 130 foot clear pathway. Our goal this year is to achieve $75 \mathrm{~m} / \mathrm{s}$ ( $246 \mathrm{ft} / \mathrm{s})$. Our model baseline concept is to achieve approximately $10 \mathrm{~g}$ acceleration which would require about $29 \mathrm{~m}(95 \mathrm{ft})$ of track and decelerate at $20 \mathrm{~g}$ 's which would require an additional $14 \mathrm{~m}$ of track. Thus the total track length required $43 \mathrm{~m}(141 \mathrm{ft})$. If we do not achieve the $10 \mathrm{~g}$ acceleration we will consider extending the track outside the building where an additional $15 \mathrm{~m}$ of track can be accommodated. An Operational Safety Procedure for the experiment in Building 435 has been prepared and is in the review process.

Aerodynamics: A $\$ 50 \mathrm{~K}$ contract with Penn State is being processed for support work on the aerodynamics of the launch cradle. The goal is to achieve a design that minimizes both vertical loads and moments due to aerodynamic forces. 
Full scale Bantam: Also, during the period we received more information on the parameters required for Bantam, i.e., launch weights in the $100,000 \mathrm{lb}$ to $300,000 \mathrm{lb}$ class with an acceleration/deceleration limit of $3 \mathrm{~g}$. These information will be factored into our future studies on new estimates of the size and cost of a full-scale magnetic launching system based on the Inductrack concept. Side loads (torques) generated by cross winds are being considered for the first time. If side load requirements are severe it may lead to a track design using two parallel coil rails instead of the one rail current design. We have requested more information on estimates of the maximum side loads expected.

The figure below estimates the energy storage requirements for a $123 \mathrm{~m} / \mathrm{s}(400 \mathrm{ft} / \mathrm{s})$ launch system at three different inclination angles as a function of the combined vehicle and launch cradle mass. Currently we would recommend that the cradle mass be assumed to be about $10 \%$ of the vehicle mass. Thus a 200,000 $\mathrm{lb}$ vehicle (about 100,000 $\mathrm{kg}$ including a $10 \%$ mass cradle) launched at an inclination angle of 15 degrees would require about $2 \mathrm{GJ}$ of stored energy. If charging the energy storage system took 5 minutes, it would require a total power of only $7 \mathrm{MW}$. At $\$ 0.08 / \mathrm{kWh}$ (the current national average) the "fueling cost" is less than $\$ 45$.

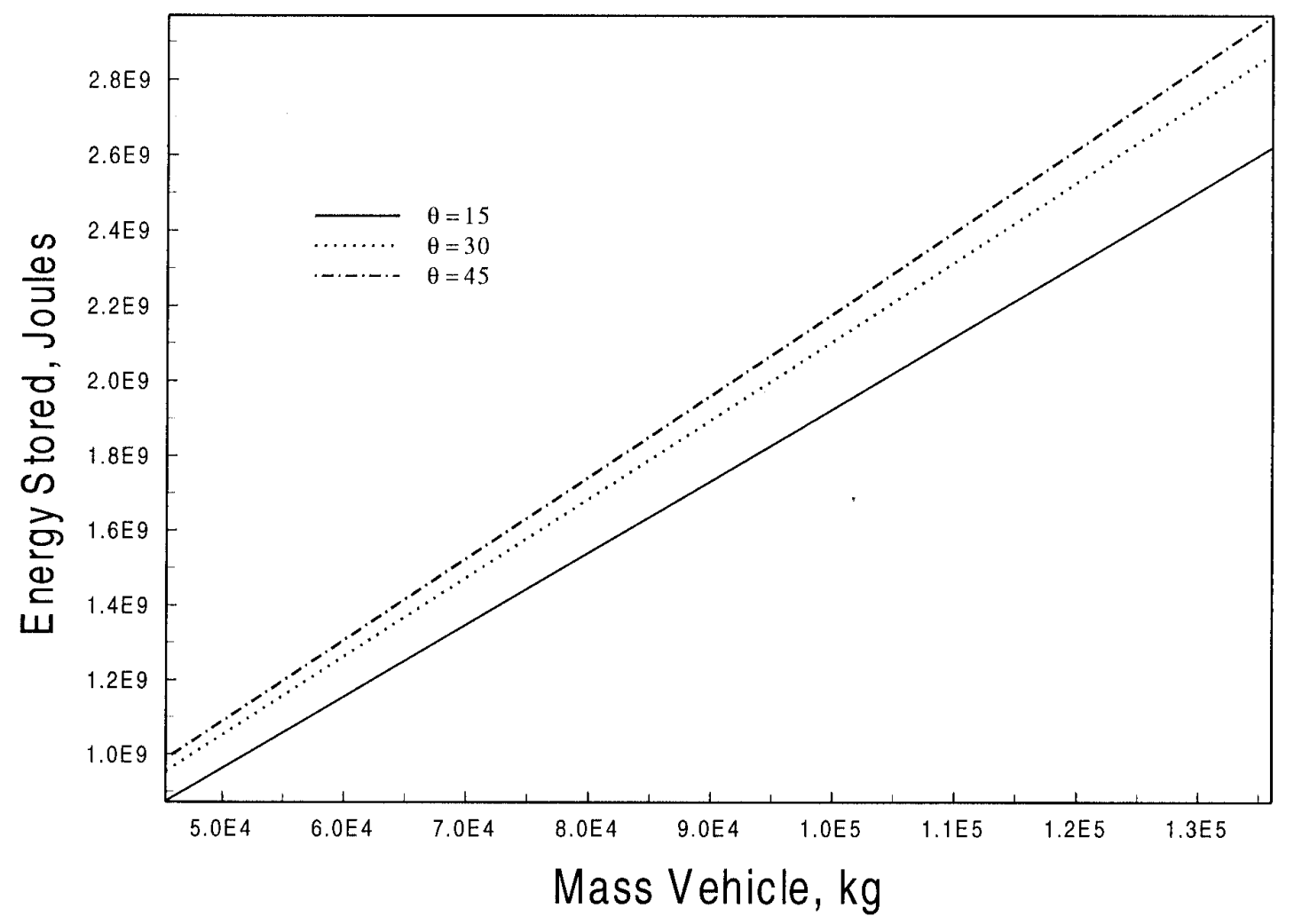

Ray Smith

Lead Engineer

$3 / 2 / 99$ 


\section{LLNL Inductrack Progress Report: Mar. 1-Apr. 151999}

Financial: Expenditures in March were \$20,269.

\section{Accomplishments:}

General

As of April $6^{\text {th }}$, Louann Tung replaced Ray Smith as lead engineer and Tony Ladran as project engineer. However both are still available for consultation until she achieves the critical speed needed for the project. Thus the project assignments described in our February report are now changed to the following:

Lead scientist:

Lead engineer:

Capacitor bank and drive circuit design:

Track design and fab

and experiment operator:

Launch cradle design

and dynamic analysis:

Launch cradle fab:

Aerodynamics:
Dick Post

Louann Tung

Ed Cook

Bill Kent

Joel Martinez-Frias

Nick Patz (Engineering summer student)

Penn State (Professor George Dulikravich and students)

In the next few weeks, we hope to provide NASA with a revised schedule and budget.

\section{Launch cradle}

We have met with representatives from Ugimag - a magnet supplier that manufactures magnets to custom specifications in their own facility. They will be providing us with a cost estimate for three options: magnets only, assembled in a group, or assembled in aluminum box to mount on our cradle. The time between placing the order and receiving magnets is 4 weeks if parts are available or up to 8 weeks if new magnet blocks need to be pressed.

\section{Track circuitry}

Studies have been made toward finalizing the design of the Inductrack levitation and drive coil circuits. Much simplified designs for both of these circuits were achieved, as compared to those employed in the existing Inductrack model.

The initial drive coil circuit design called for a $7 \mathrm{kA}$ drive current, but calculations regarding the amount of copper required for reasonable losses indicated that this approach was unreasonable. Subsequently, we have looked at a three turn layout (within the $1 \mathrm{~cm}$ spacing available) that would only require $\sim 2300$ amperes. We have also talked with a vendor that specializes in manufacturing heavy copper printed circuit boards and they have made suggestions that would improve manufacturability. They are currently waiting for more information from us regarding the modified layout and how the three turns would be connected together. 
Owing to the multi-g accelerations that will be required, with its accompanying requirement for multi-kiloamp currents in the drive coils, it is important to minimize the inductive coupling between the drive coils and the levitation coils. Also, since the drive power levels are high, the losses in the levitation coils will remain small compared to these levels even for much-reduced coil cross-sections. As a result the construction of the levitation coils can be greatly simplified. We propose to construct modular sections of the drive coil simply by winding a single layer of enameled copper wire (\#10 gauge) on an insulated form, and then closing the circuit on each turn by stripping the insulation from a wide area on the lower surface and flowing solder between the turns. This will form a close-coupled set of single-turn shorted circuits, forming the levitation coil system. These levitation circuit modules, each approximately one quarter-wavelength long in the axial direction, will then have the drive coils interleaved between them. These latter coils, which are presently planned to be constructed as printed circuit elements, consist of a short stack of back-to-back, single-turn, coils. One of each pair couples closely to the Halbach arrays on the cradle, while the other, a mirror-image of the first, cancels the flux that would otherwise be induced in the adjacent levitation coils. In this way the two circuit assemblies (levitation and drive) are made to be electrically independent of each other. In the coming period the mechanical design of the track system will be finalized, in preparation for sending the assemblies out for bids on their construction.

\section{Track Support}

Calculations have been done to design the square steel beam and the fiberglass I-beam that supports the track. Two 20-foot beams have been purchased - one is a 7 " square steel beam and the other is a 6" fiberglass I-beam. We are awaiting quotes from vendors for commercial stands.

\section{Simulation}

Funds for the $\$ 50 \mathrm{~K}$ contract with Penn State should be available this month for Penn State to do support work on the aerodynamics of the launch cradle.

We have purchased a one year seat with ANSYS - a finite element code for integrated structural, dynamic, and electromagnetic analysis. A three dimensional complete model of the cradle and track have been meshed.

\section{Louann Tung Lead Engineer $4 / 19 / 99$}




\section{LLNL Inductrack Progress Report: Apr. 15 - May 15, 1999}

Financial: Expenditures in April were $\$ 39,900$.

\section{Accomplishments:}

General

- Our Operational Safety Procedure has been written and is in the process of getting final signature approval.

- Our contract with Penn State to model the aerodynamics of our launch cradle has been signed off so that they can begin work.

- A revised detailed budget and plan between Feb. 1, 1999 and Feb. 1, 2000 was crafted and sent to NASA.

- We have added Blake Kreitzer - an electronics technician - to our team for the next four weeks to help in the electronics design of the drive circuitry.

- We are preparing for the arrival for our two summer students in June.

- We have renamed our project Inductrack 2000 to distinguish this year's project from the previous and future generations.

\section{Launch cradle}

- We have begun work on an ANSYS analysis of the stresses induced in the launch cradle from the opposing repulsive forces of the three magnet arrays. With this analysis, aluminum was found to be unacceptable for the final design due to the additional weight needed to provide sufficient strength. Hence we are considering Cfiber composite as the material of choice. In addition a pocket could be molded within the C-fiber cradle to assist in holding the magnet arrays in place. This will aid in withstanding the possible maximum force provided by $40 \mathrm{~g}$ 's of deceleration (see below). An interim choice using aluminum may be considered because of the additional uncertainties in making a $\mathrm{C}$-fiber cradle. The details of this design are in progress.

- The magnet design is finalized. Ugimag has provided a quote of $\$ 2712$ for a set and one spare of the 6 arrays ( 5 each) of magnets that we need ( 60 magnets in total). They suggest that we use Class $38-\mathrm{NdFeB}$ magnets that have a $\mathrm{Br}=1.26 \mathrm{~T}$ and $\mathrm{Hci}=12$ kOersteds. They are currently investigating the method and costs of bonding the magnet arrays in one unit. The time of delivery is 10 weeks. We expect to make our purchase soon after receiving their input on bonding. In addition, Dr. David Carnegie at Ugimag has run Amperes (a 3d magnetostatic code) to predict the magnetic flux of our arrays. A contour plot is shown on the next page. The location of the fields perpendicular to the surface identifies the spacing needed for our drive coils. This spacing (center-to-center) is about $5.8 \mathrm{~cm}$. 


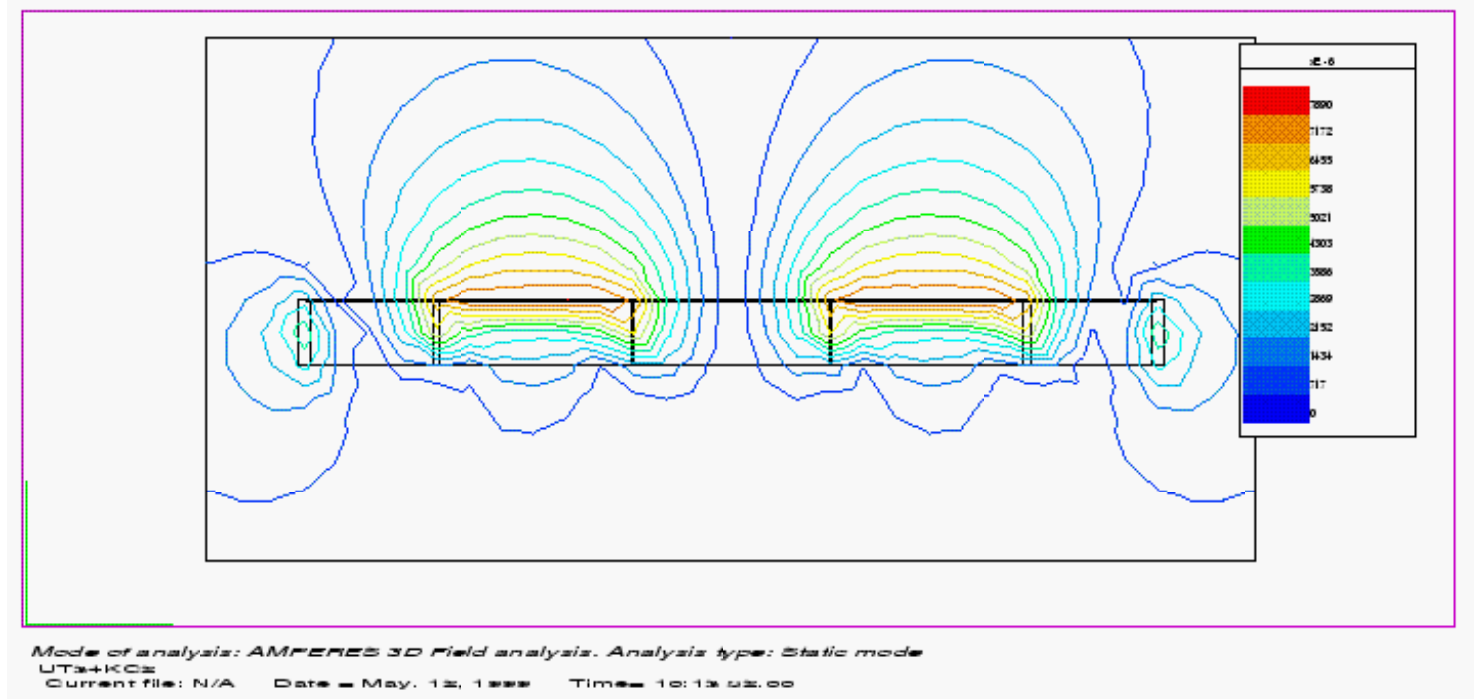

Figure 1. 3-d plot vector potential contours as calculated with Amperes (by Ugimag) for 13-cm long array of $5 \mathrm{NdFeB}$ (Class 38) magnets. Orientation is up-side-down since our flux is concentrated on the bottom of the magnets.

\section{Track Support}

- Floor stands for the track support and a granite block (for use as an emergency momentum trap at the end of the track) have been found on-site at no cost.

- Surveyors have determined the levelness of the floor and marked the locations for our track supports.

\section{Deceleration system (by R. F. Post)}

An important element of the NASA model Inductrack system is the deceleration section at the end of the track needed to slow and safely stop the launch cradle. A similar system would be required in a full-scale Inductrack rocket launcher system. Theoretical analyses and preliminary design calculations have been made of a very simple, totally passive, system that meets the requirements of our model system.

In our model system the targeted acceleration rates will approach $10 \mathrm{~g}$ 's. Such high accelerations, although higher than those projected for a full-scale launcher, are needed in our case to reduce the length (and cost) of the track. For the same reason we need to achieve as high, or even higher, deceleration rates following the acceleration. In fact, we are designing the model launcher vehicle to withstand deceleration forces of order $40 \mathrm{~g}$, thereby substantially reducing the required total length of the track as compared to that required if the deceleration rate is limited to $10 \mathrm{~g}$.

There is, fortunately, a very simple way to accomplish this objective with minimal cost and complexity. The previously derived theory of the Inductrack includes a consideration of the levitating and drag forces that would arise if the close-packed circuits of the track were to be replaced by a sheet of conducting metal, stainless steel, for example. Although the levitating and centering forces would not be appreciably degraded, the drag forces would be greatly increased, owing to the high electrical 
resistivity of stainless steel. In this way multi-g deceleration rates can be achieved, in a highly controllable way, and without loss of levitation during the deceleration.

The theory shows that in the case at hand the drag force (arising from resistive losses associated with eddy currents induced in the conducting sheet) is proportional to the product of the area of the Halbach array and the electrical skin depth. Since the skindepth depends on the frequency of excitation, thus upon the speed of the vehicle, the relationship between drag force and speed (above a low critical speed) can be expressed by an equation of the form:

$$
\mathrm{F}_{\text {drag }}=\mathrm{K} / \mathrm{v}^{1 / 2} \quad \text { Newtons, }
$$

where the parameter $\mathrm{K}$, varying with the square root of the resistivity of the conducting sheet, is in addition proportional to the product of the area of the Halbach arrays and an exponentially decreasing term dependent on the separation gap between the surface of the Halbach arrays and the surface of the conducting sheet. The resistivity of stainless steel (or that of ordinary yellow brass) is high enough to yield $\mathrm{K}$ values that can produce the desired deceleration rates. With the above-given dependence on velocity of the drag force an equation can be derived giving the stopping distance, $\mathrm{S}$, for the cradle. This equation is:

$$
\mathrm{S}=\frac{2}{5}\left[\frac{\mathrm{M}}{\mathrm{K}}\right] \mathrm{v}_{0}^{5 / 2} \quad \text { meters }
$$

where $\mathrm{M}(\mathrm{kg})$ is the mass of the launcher vehicle and $\mathrm{v}_{0}(\mathrm{~m} / \mathrm{sec}$. $)$ is its velocity at the starting point of the deceleration section.

As an example, if stainless steel sheets are used in the deceleration section, spaced with a gap of $0.7 \mathrm{~cm}$ from the surface of the Halbach arrays, an initial deceleration rate of $40 \mathrm{~g}$ is predicted. If the velocity of the model launching vehicle after acceleration is $100 \mathrm{~meters} / \mathrm{sec}$ this leads to a stopping distance of approximately 10 meters.

Louann Tung

Project manager

$5 / 14 / 99$ 


\section{LLNL Inductrack Progress Report: May 15 - June 15, 1999}

Financial: Expenditures in May were $\$ 42,228$.

\section{Accomplishments:}

\section{General}

- Our Operational Safety Procedure has been approved. We will begin taking our required safety classes.

- Our two summer students Brian Smith and Nick Patz have arrived and are going through orientation.

- Upon a request from the CEO of the High-Speed Ground Transportation Association, Dick Post prepared a presentation on Inductrack-related work at the Laboratory for the Association's annual meeting in Seattle, 7-8 June. The meeting represents an important forum for the discussion of maglev and other high-speed rail systems. The presentation described the Inductrack concept, reviewed its application to NASA missions, and outlined the model system for NASA under construction.

\section{Launch cradle}

- We have begun work on a 3-d ANSYS analysis of the stresses induced in the launch cradle from the opposing repulsive forces of the three magnet arrays. We concluded last month that aluminum was found to be unacceptable for the final design due to the additional weight needed to provide sufficient strength. However after the addition of ribs, an acceptable design for an aluminum cradle was created as seen in Fig. 1. This design is fabricated by bending $1 / 8$ " aluminum sheet into the C-shape shown and cutting the openings shown to reduce weight. Ribs are then welded onto the sheet.

- With this cradle model, we are in the process of examining the modes that can be excited in this structure. This will enable us to add in the proper energy dissipation via shock absorbers if instabilities become severe. For our low speed tests, shock absorbers will not be added. A complex modal analysis could prove very timeconsuming but necessary for future upgrades.

- The magnet design was finalized and 12 magnet arrays (includes a spare set) were ordered from Ugimag. Delivery is expected in mid-August.

- We have completed a 3-d ANSYS model of the Halbach magnet arrays. Figures 2 - 5 show various profiles of the magnetic field. Note that the axis shown in Fig. 1 is orthogonal ( $x$ and $z$ are switched) to the one used below in the magnet analysis.

A) In Fig. 2, the magnetic field normal to the bottom surface, $B_{y}$, is shown as a function of $x$ (parallel to the surface) at $y=1.0 \mathrm{~cm}$ and $z$ at the array center. The location of the $B_{y}(x)$ peaks determines the location of the center of the drive coils. Thus as seen in Fig. 2, the drive coils must be centered at $5.0 \mathrm{~cm}$ apart. Also in Fig. 2 is shown $B_{x}(x)$ at $y=1 \mathrm{~cm}$. If the Halbach arrays had a large number of magnets along the $x$-direction, then $B_{x}(x)$ and $B_{y}(x)$ would be sinusoidal and be $90^{\circ}$ out of phase. However due to our 5 magnet length, $B_{x}(x)=$ -0.08 Tesla (rather than 0 ) when $B_{y}(x)$ is at a peak - as seen in Fig. 2. This may cause some vertical deflection along $y$ where we expect to only be applying an acceleration along $x$. We are discussing ways to predict the outcome of this situation and mitigate the consequences. 
B) In Fig. 3 is $B_{y}(y)$ at the center of the array. The theory for the fundamental of the field for an infinite array compares well with the calculation.

C) The uniformity of the field along $z$ (along the short direction of the track) is shown in Fig. 4.

\section{Track Support}

- All 7 inch square tubes for the strong back assembly have been received.

- The Inductrack hall was precision surveyed and the alignment bench marks laid out.

- All seven aluminum track stands were installed, leveled, and grouted.

- The end wall was opened and access door installed .

\section{Acceleration system}

The coils shown in the drawings in Fig. 5 were designed and pc boards are being fabricated for test purposes. The symmetry of the front and back side of the boards is required to minimize the interference between the drive coils and adjacent levitation coils. The resistance and inductance of these boards both individually and as an assembly (1-5 boards in the assembly correspond to $1-5$ turns for the drive coil) will be measured. Based on these measurements, the electrical design for the pulse drive circuit can be finished.

The control electronics for the drive circuit and different scenarios for operation are in the process of being designed.

\section{Louann Tung}

Project manager

With input from team members Ed Cook, Joel Martinez-Frias, Bill Kent, and Dick Post. $6 / 15 / 99$ 


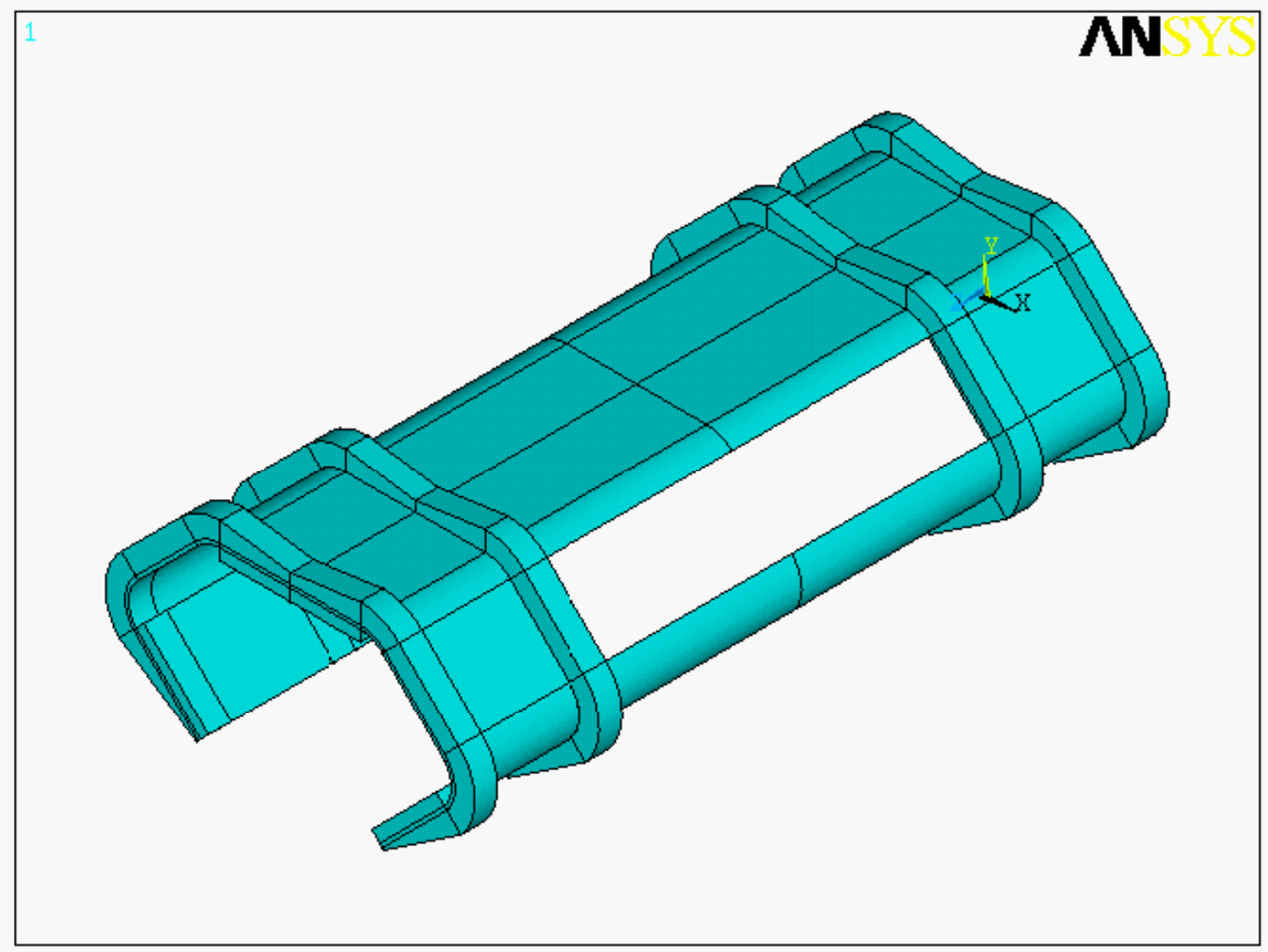

Figure 1. Aluminum cradle design. 


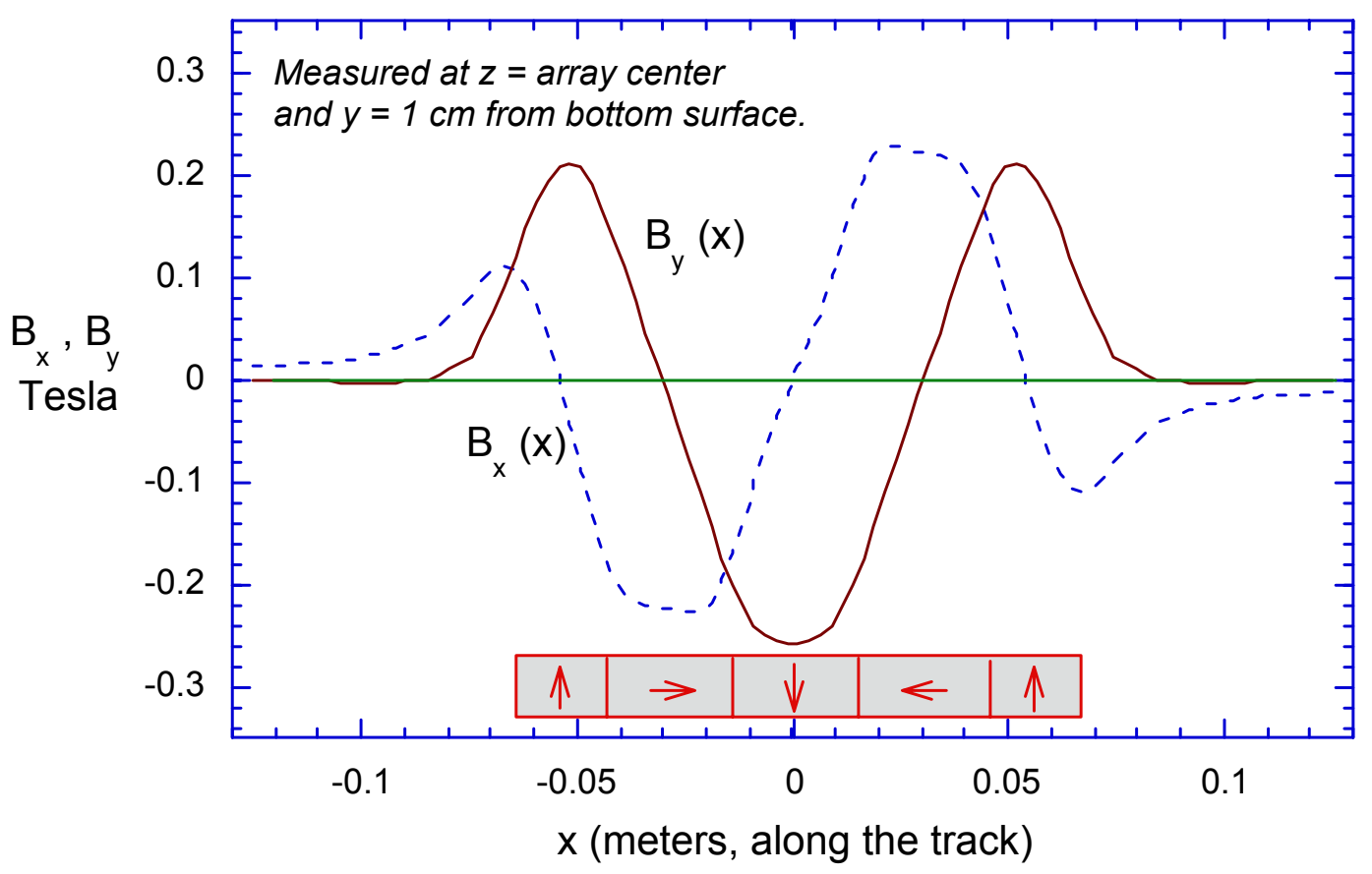

Figure 2. Variation of $B_{x}$ and $B_{y}$ along the track (in $x$ ) indicating the nearly sinusoidal behavior as expected. 


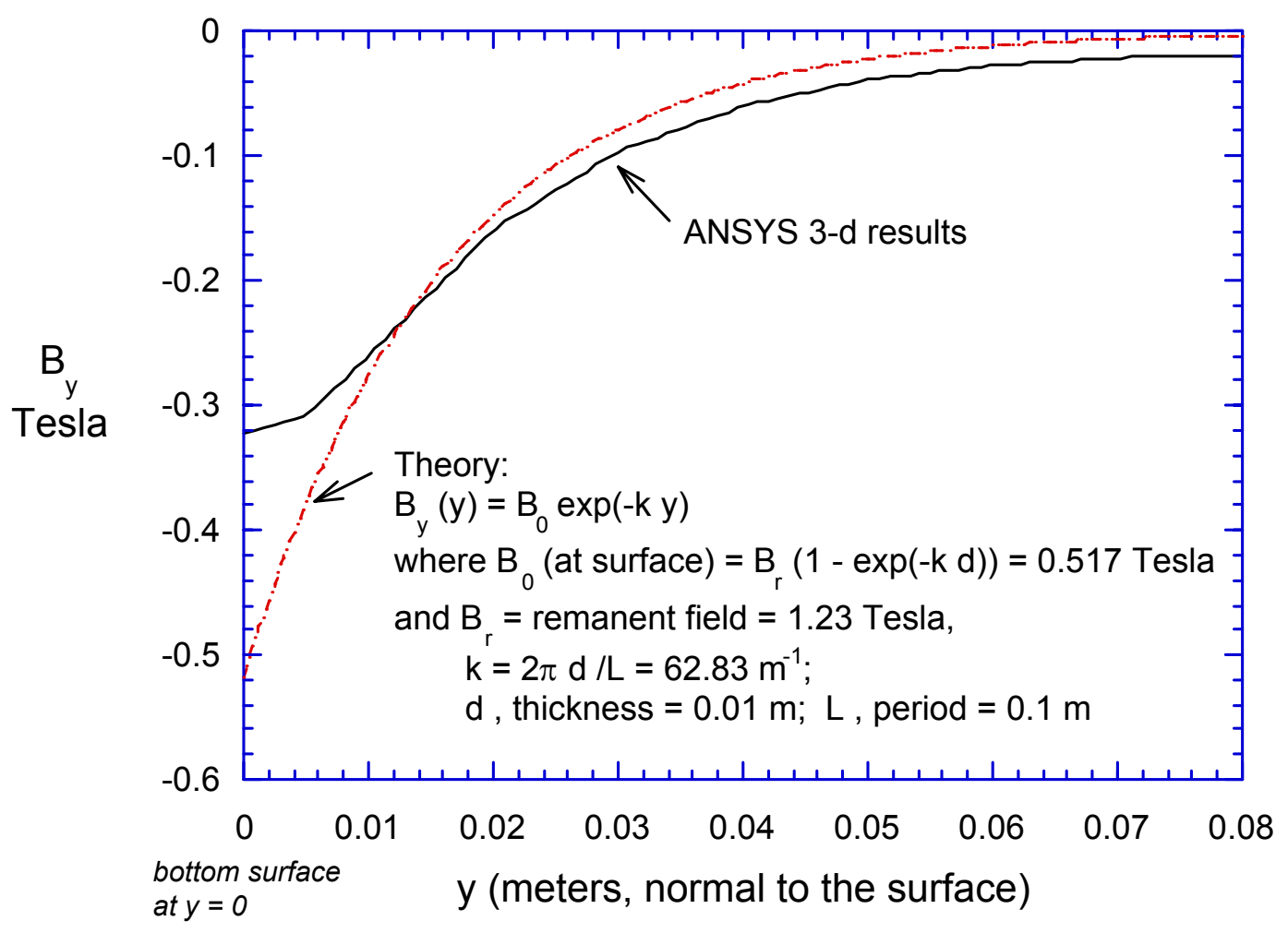

Figure 3. Variation of $B_{y}$ away from the bottom surface of the Halbach array calculated at center of array. Theory is shown for an infinitely long array of magnets. We expect to operate between $\mathrm{y}=0.005$ and 0.1 meters from the surface. 


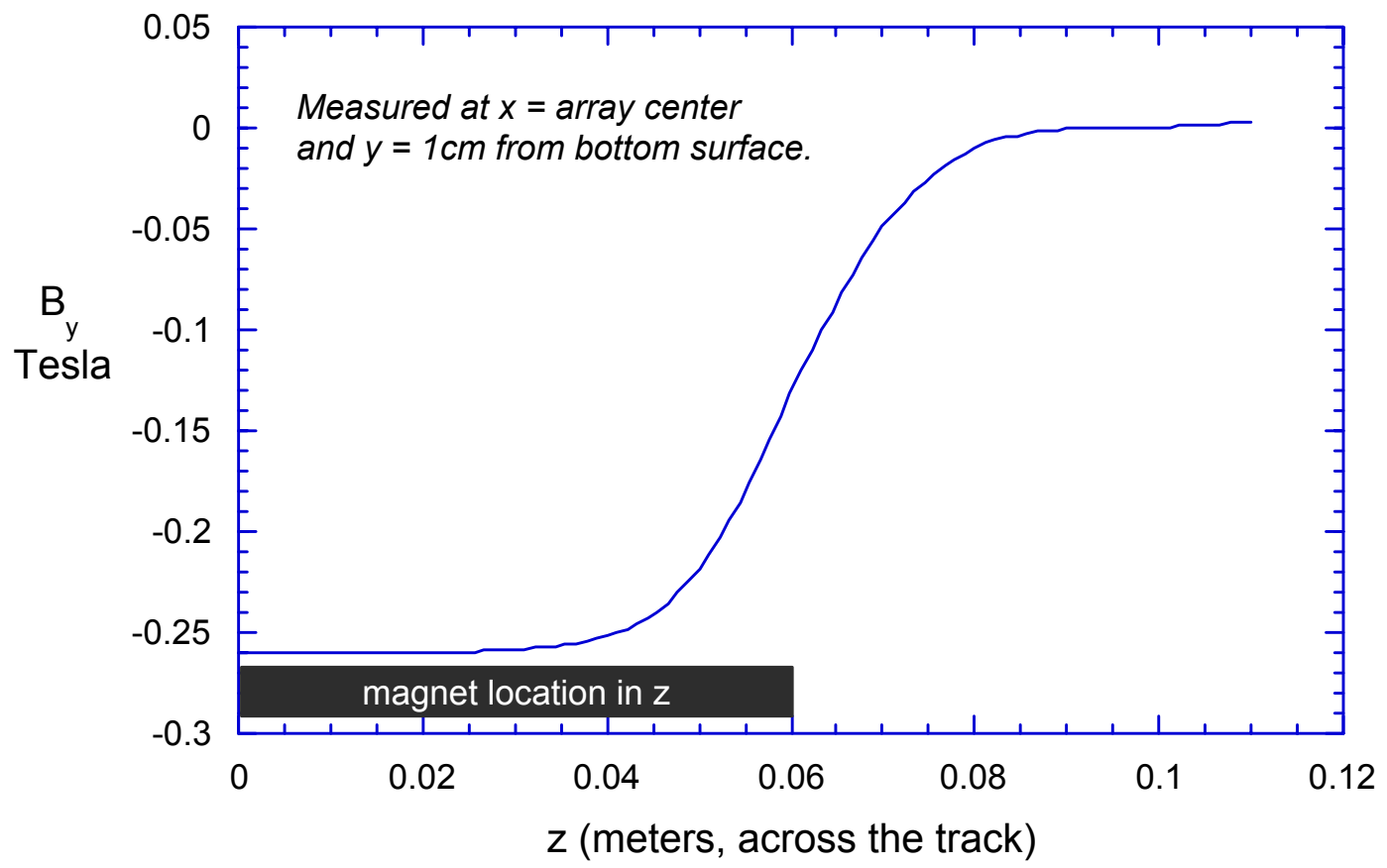

Figure 4. Variation of $B_{y}$ across the track indicating that the field across the central $8 \mathrm{~cm}$ (out of $12 \mathrm{~cm}$ ) is very uniform. 

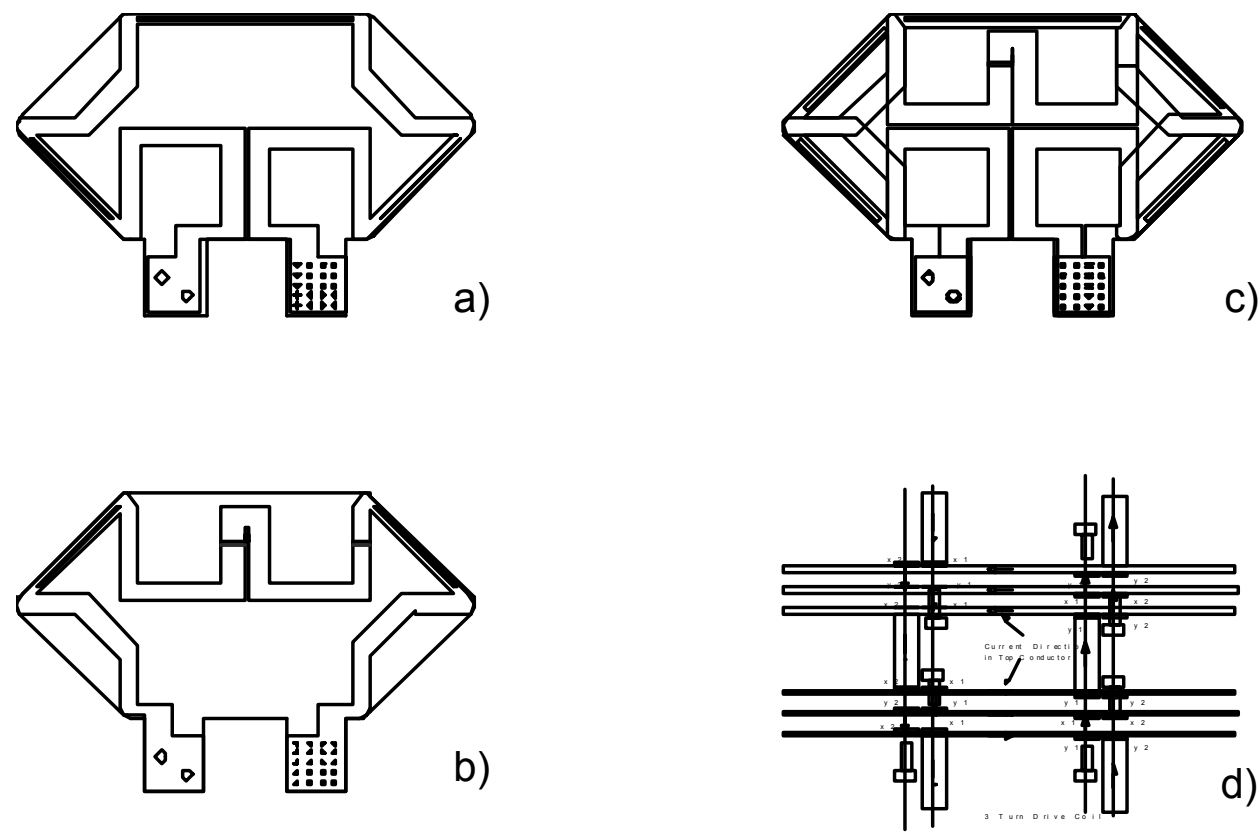

Figure 5. Prototype of copper pattern for drive coil layout. a) Front view of front side of printed circuit card. b) Front view of back side of same card. c) Overlay of front and back coil on same board showing symmetry. d) Exploded view from the top of an assembly of boards and interconnections. 


\section{LLNL Inductrack Progress Report: June 15 - July 15, 1999}

Financial: Expenditures in June were $\$ 52,059$.

\section{Accomplishments:}

\section{General}

- We are in the process of closing our contract with Penn State and starting a new one with University of Texas at Arlington because of Prof. Dulikravich's change in employment. He will begin in Texas on Aug. 1. He has already spent $\$ 13,346$ on computing equipment which will also be transferred to Texas. The subcontract with the University of Texas will be for $\$ 40,000$ to be spent between Aug. 1, 1999 and Jan. 31, 2000. Prof. Dulikravich and his graduate students will model the aerodynamics of our cradle.

- Two days of work was lost due to the DOE mandated security immersion training for all LLNL employees.

- A new electrical engineer Dan Shimer will be joining us around the week of July 14 to assist us over the next month in the design and prototyping of the control and timing circuits, the drive coils, and photo sensor diagnostics.

\section{Launch cradle}

Our summer student Nick Patz from Cal Poly has extensive experience in building carbon fiber composite components and has access to YLA - a nearby company where he can build the cradle. Hence we have chosen to design and build a carbon fiber cradle for this year's testing. Joel and Nick have used ANSYS to design the cradle. The 3-d model is shown in Fig. 1.

The following was provided by Nick.

The advantages of carbon fiber compared to common metal alloys lies in its orthotropic nature. The term unidirectional comes from the symmetrical direction of fiber orientation while the term prepreg is an abbreviation of the word pre-impregnation. The resulting phrase unidirectional prepreg thus describes multiple fibers in the same direction held together by a matrix. It is commonly known that strands of carbon fiber have an extremely large modulus in tension much like a string, while resin systems such as epoxies and cyanates act very much like concrete displaying a large compression modulus but a very small modulus in tension. These specific properties allow for the development of very light and very strong composite structures that uses their orthotropic nature to counter the known loads with a minimum amount of material.

Designing composite structures, although advantageous, proves to be difficult for many reasons. First the thermal contraction of carbon fiber is not trivial if a composite is created that does not have a balance of directional fibers it contracts in different amounts in different directions causing warping. Warping can be avoided by simply balancing the unidirectional prepregs. The next problem is the difficulty of modeling composite structures. Each lamina (a ply of unidirectional prepreg) has a definite modulus of elasticity and shear. When multiple laminae are together (a laminate) the directional modulus of the resulting laminate can be predicted using a involved set of equations placed in a spread sheet to yield a resulting modulus and poisson's ratio for use as input 
into a finite element analysis program. Other problems involve bonding and mounting of the composite structures to other structures.

A conceptual design of the carbon fiber cart has been developed (Figure 1). A parametric based model has been crated in the ANSYS-code to obtain the optimum mechanical rigidity while decreasing the weight of the cart. The 3-dimensional structural analysis considers the orthotropic properties of the carbon fiber stated above. The preliminary results show that with a cradle speed of $75 \mathrm{~m} / \mathrm{s}$ a maximum displacement of the bottom of the stabilizing Halbach array was found to be between $0.15 \mathrm{~cm}$ and $0.07 \mathrm{~cm}$. The resulting mass, excluding the Halbach arrays, is approximately $4.16 \mathrm{~kg}$ compared to the aluminum of $4.6 \mathrm{~kg}$ implying a total carbon fiber cradle weight savings of $10 \%$. It should be stated that these are preliminary results further analysis of the cradle will involve optimizing the weight to strength ratio through an iterative process.

\section{Track}

- A full-scale model of an assembly of a section of track was made. This was done to improve the visualization of how the drive and levitation coils would be assembled and how the cradle and its guide would wrap around the track. A photo of this model is shown in Fig. 2.

- Improved the support structure of the ceiling in the lab to improve safety.

- Track Installation continues: 7 " sq beams being prepared for paint, Stud welder secured and tested.

- Received and inspected 6 " channel. Design work for assembly and mounting to 7" sq tube complete.

- Change from I beam to channel construction reduced component cost by $60 \%$ and solved assembly problems.

\section{Louann Tung}

Project manager

With input from team members Joel Martinez-Frias, Bill Kent, Nick Patz, and Brian Smith.

7/13/99 


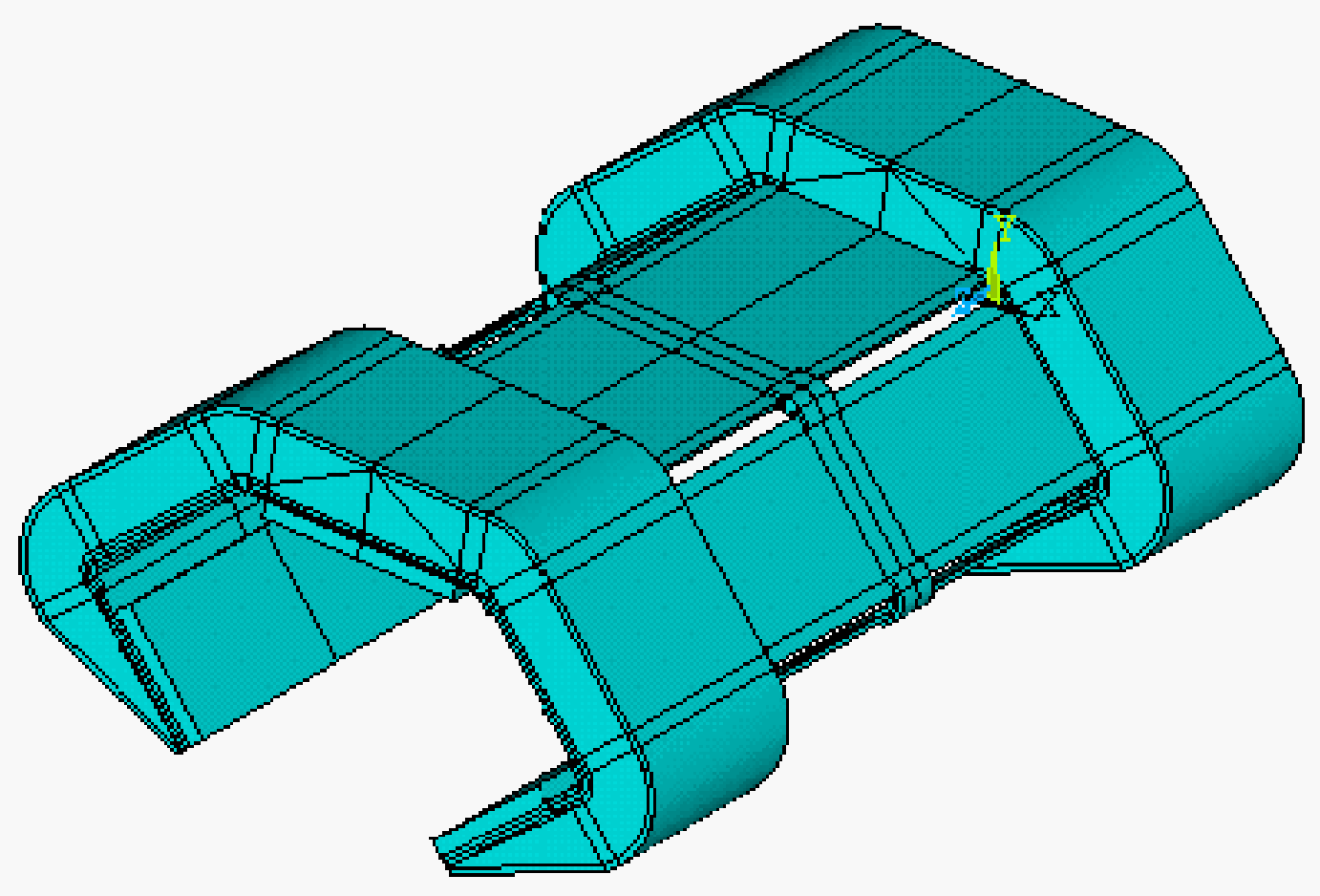

Figure 1. Carbon fiber composite design for the cradle using ANSYS.

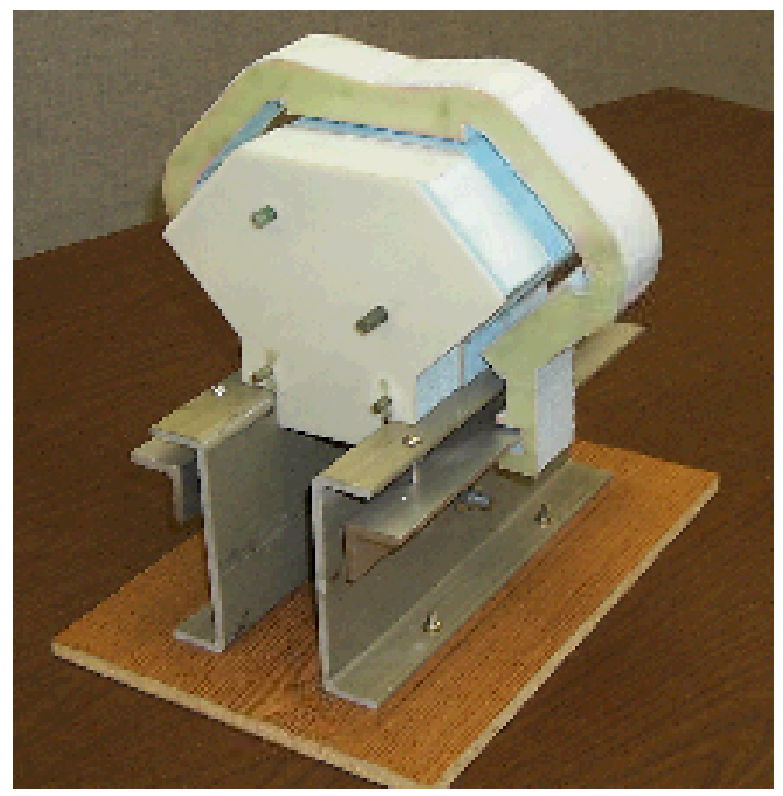

Figure 2. Photo of model of drive and levitation coil assembly. Note how the C-shaped teflon guide and rail will prevent the cradle magnets from touching the track prior to levitation 


\section{LLNL Inductrack Progress Report: July 15 - August 15, 1999}

Financial: Expenditures in June were \$71,284.

\section{Accomplishments:}

General

- We started a subcontract with the University of Texas at Arlington because of Prof. Dulikravich's change in employment. The subcontract with the University of Texas will be for $\$ 40,000$ to be spent between Aug. 1, 1999 and Jan. 31, 2000. Prof. Dulikravich and his graduate students will model the aerodynamics of our cradle.

- We are beginning to determine the exact costs of the electronic components. The drive circuitry is proving to be an expensive component. We are in the process of assessing what final velocities are achievable with the funds available.

\section{Drive circuit design by Dan Shimer}

A new drive coil was designed using \#6 square insulated magnet wire. It has one turn and includes a series compensating winding to prevent magnetic coupling to the adjacent levitation coils. The \#6 square wire is the largest wire size that fits in the $1 \mathrm{~cm}$ allotted space. Calculations indicate that the skin effect is small with the ac resistance less than ten percent higher than the dc resistance. The design using square magnet wire was selected over the printed wiring board design to maximize the amount of copper and thereby minimize the resistance. It was also selected over machined copper plates because of cost. The preferred design controls the current path more precisely than the wide conductors used in the two alternative designs and therefore should have the best performance.

Studies were done to determine the proper drive current amplitude and duration to achieve $75 \mathrm{~m} / \mathrm{s}$ at $28 \mathrm{~m}$. A peak of $7000 \mathrm{~A}$ and a pulse width equivalent to either 2.5 or $3.0 \mathrm{~cm}$ will work. (This analysis is discussed later by Nick Patz.) The optimum pulse width will be maintained over most of the 30-m track by tuning the resonant circuits in discrete intervals based on an assumed velocity/distance profile. Between zero and $4 \mathrm{~m}$ the pulse time will be kept constant.

A minimum power of $180 \mathrm{~kW}$ during $0.8 \mathrm{sec}(145 \mathrm{~kJ})$ is needed to achieve $75 \mathrm{~m} / \mathrm{s}$ at a distance of $28 \mathrm{~m}$. This is with the minimum of 6 coils energized at one time, three in the front and three in the rear of the vehicle. With only 6 coils energized together, 100 circuits are needed for a $30-\mathrm{m}$ track. Each circuit requires two costly high current thyristors and associated trigger circuitry. Energizing more coils at one time reduces the number of circuits but increases the power. A likely compromise is 8 coils in each circuit that would result in 75 circuits and $230 \mathrm{~kW}$.

A very large capacitor bank for energy storage will be required. A power supply operating from the electrical utility may be more practical. We are presently evaluating the cost of installing a $250 \mathrm{~kW}$ transformer and controlled rectifier that exists on-site at LLNL versus refurbishing and installing a very large capacitor bank.

Five hundred electrolytic capacitors have been removed from old, unused equipment and tested. They will be used as part of a much larger energy storage bank or as filtering with the $250 \mathrm{~kW}$ rectifier. 


\section{Launch cradle analysis by Nick Patz}

The cradle track interaction is complex, containing loads based on many interwoven parameters. To meet the required cradle velocity of $75 \mathrm{~m} / \mathrm{s}$ a detailed analysis of these parameters was performed. The analysis starts with assuming a sinusoidal magnetic field intensity which is comparable to the ANSYS derived magnetic field intensity at a distance of one centimeter from the Halbach array, shown in Fig. 1. This magnetic field will interact with the current for a time-dependent distance. The current pulse that drives the cradle is also assumed to be sinusoidal with respect to time is approximated as sinusoidal with respect to position.

Vertical Magnetic Field Ineraction with Current Source for One Halbach Arra)

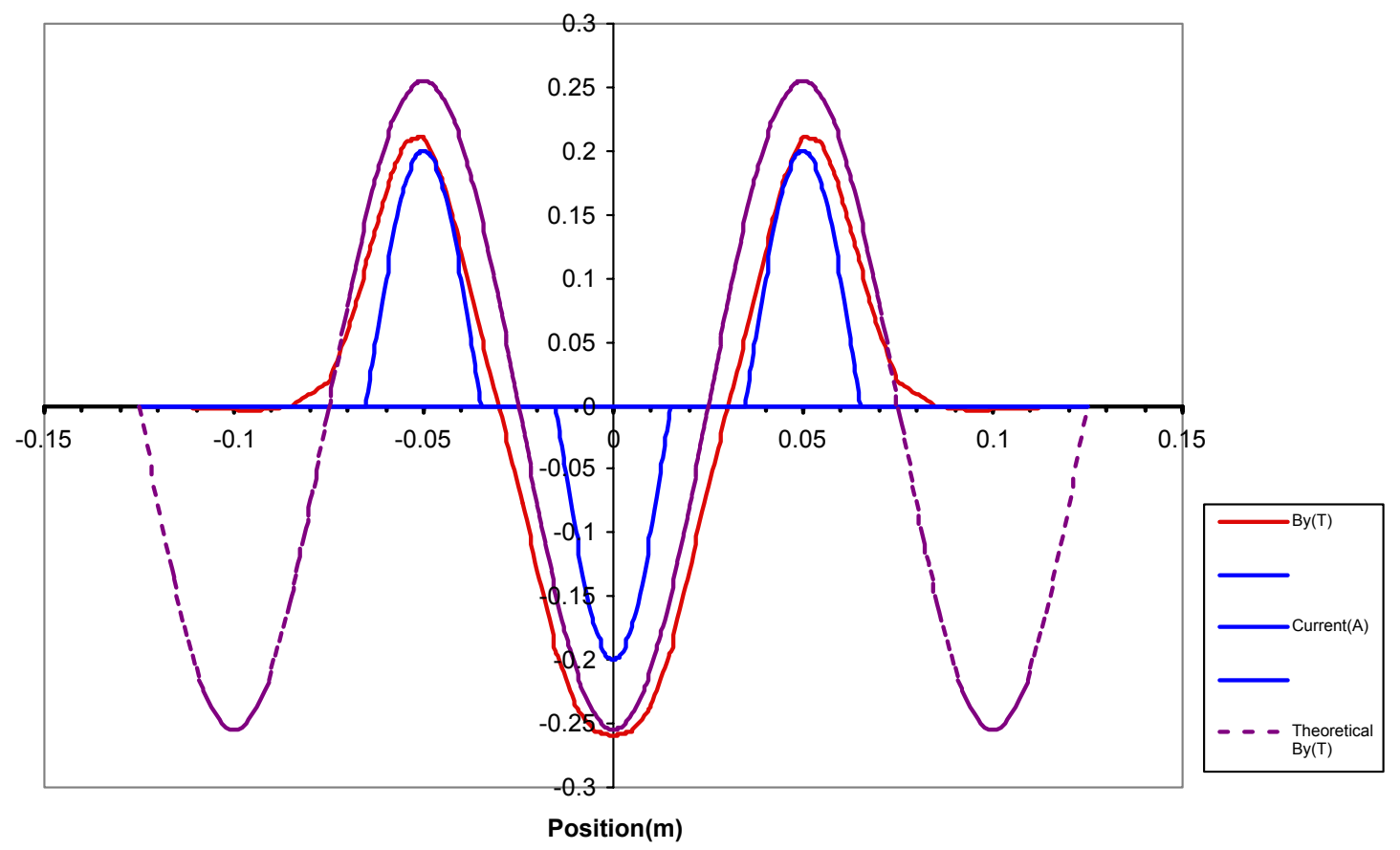

Figure 1. Current and magnetic field interaction regions producing forces in the direction of the track. The dotted line shows the theoretical, sinusoidal B-field $\mathrm{B}_{\mathrm{y}}$ normal to the magnet surface for an infinitely long Halbach array. The red line shows $B_{y}$ calculated from ANSYS for our finite-length array. The inner discontinuous blue line shows the location of current during a properly-timed pulse to give maximum acceleration. 
The acceleration force $F_{a}$ on the cradle is due to the interaction between the current in the drive coils and magnetic field. After the cradle passes beyond a set of drive coils, the on-board magnets react with the closed-loop coils that provide levitation. However this levitation effect also causes a small amount of drag. This drag force $F_{d}$ is inversely proportional to the cradle's velocity. To solve for the final velocity at the end of the track as a function of maximum current and interaction region, a spreadsheet was created that separated a single current pulse/magnetic field interaction into regions of constant force. Each region of constant force has an associated constant acceleration. This acceleration is used to yield the final velocity at the end of the region, which becomes the initial velocity of the next region. This process is repeated over the entire interaction distance. In this calculation, both the acceleration and the drag forces were accounted for, although the drag was comparably less. Repeating this acceleration-drag cycle over the length of the track yields many valuable pieces of information, most importantly it yields the final velocity of the cradle with the given parameters. Figure 2 depicts the relationship between maximum current and interaction region.

Optimization of Acceleration Parameters

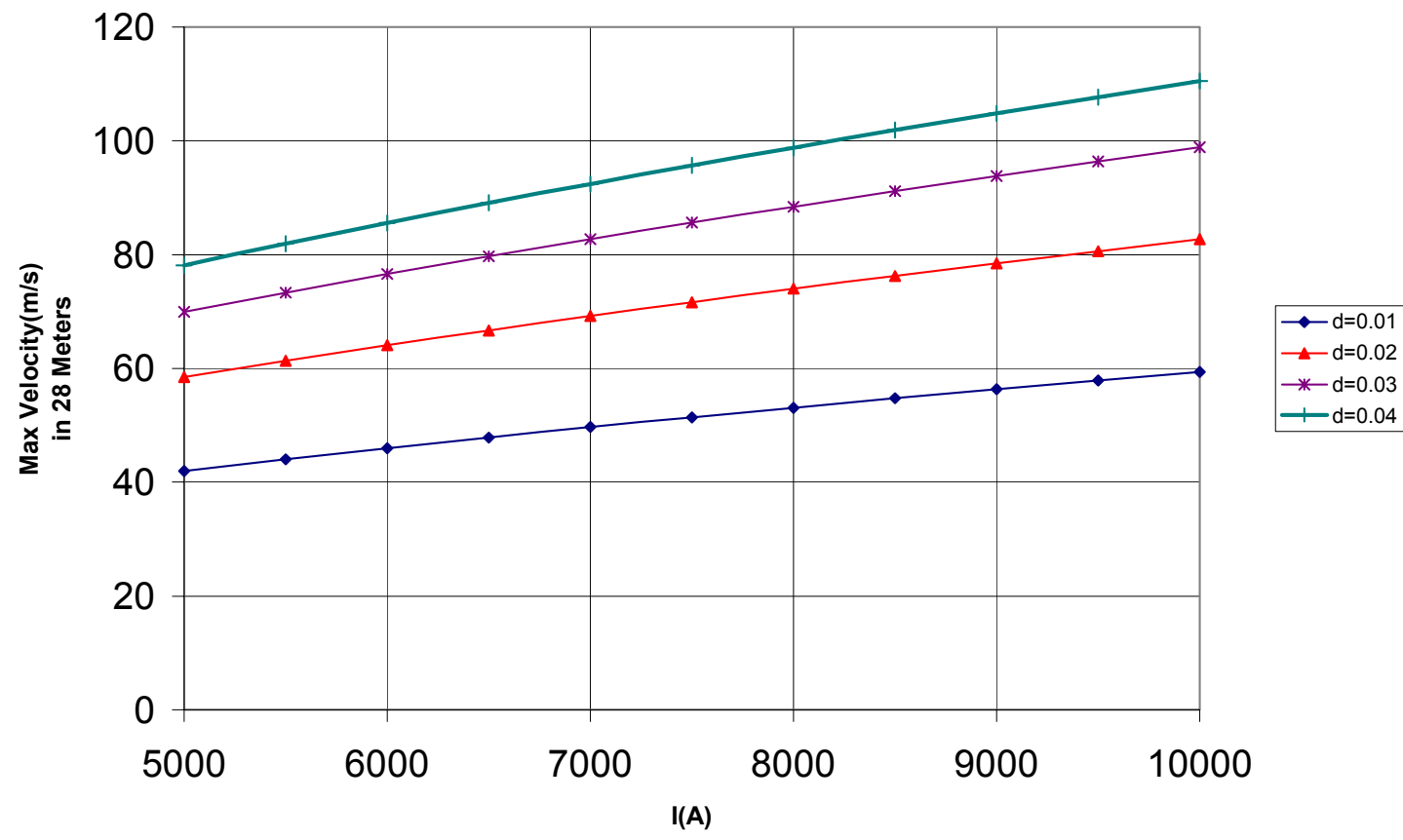

Figure 2. The interaction region $d$ and current $I$, influences on maximum velocity. 
Another important theoretical situation analyzed was the vertical perturbation due to the horizontal component of the magnetic field interacting with the drive current. Due to the negative damping in the levitation coils a small vertical loading of the cradle can result in failure. A spreadsheet was developed to analyze the drive coil location with respect to Halbach array position as well as current and interaction region. Shown in Fig. 3 , the results were as suspected. When the peak of the drive coil current is perfectly aligned with the maximum vertical component of the magnetic field the vertical perturbation is non-existing but with the slightest miss alignment or miss timing of the drive coils the vertical load rises. This analysis predicts a possible method for tuning the cradle by observing the vertical displacement during each run. When the cradle is perfectly timed there will be no vertical displacement and the maximum acceleration will be reached.

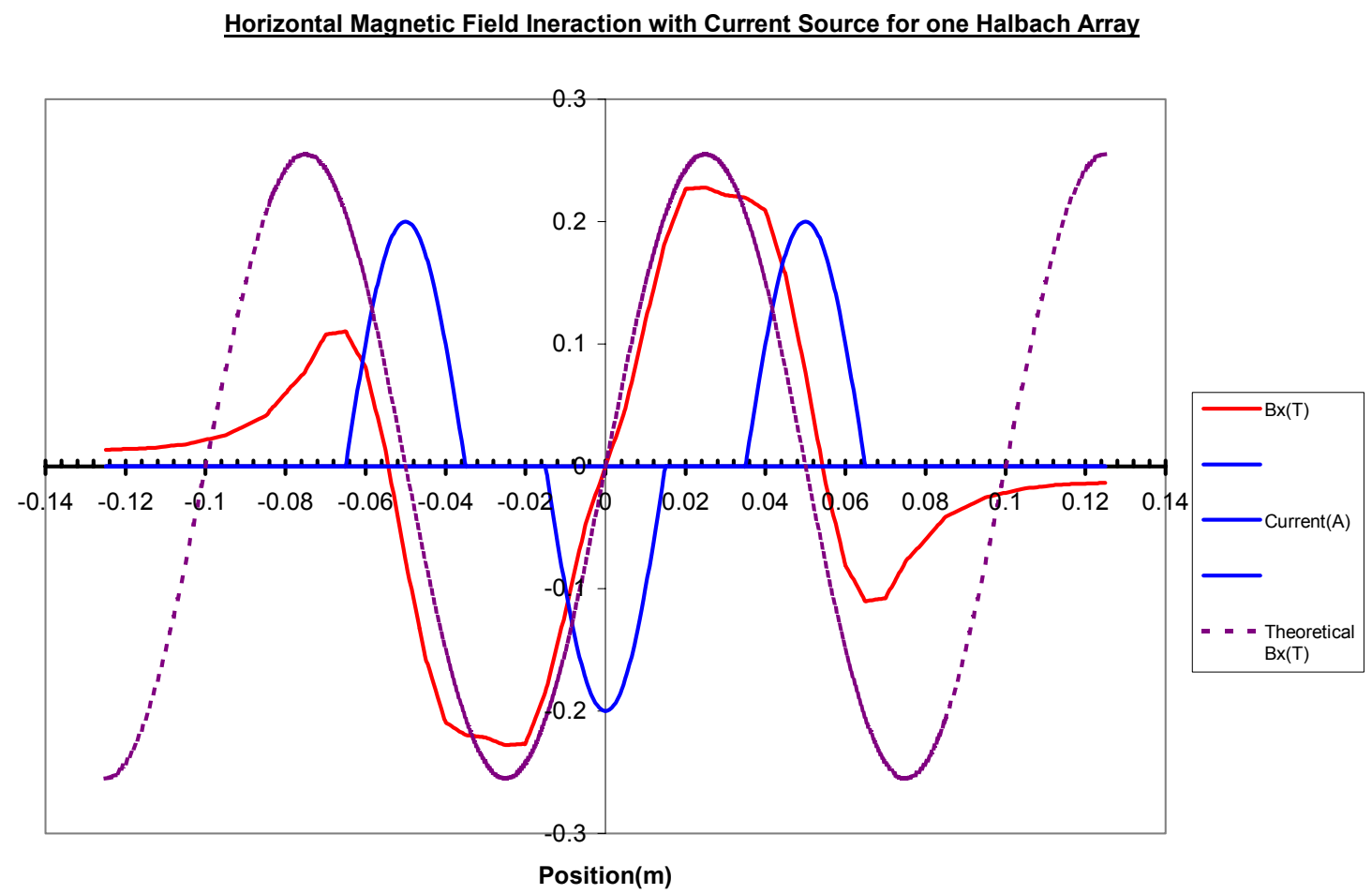

Figure 3. Current and magnetic field interaction regions producing forces in the direction perpendicular to the track. The dotted line shows the theoretical, sinusoidal B-field $\mathrm{B}_{\mathrm{x}}$ parallel to the magnet surface for an infinitely long Halbach array. The red line shows $B_{x}$ calculated from ANSYS for our finite-length array. The inner discontinuous blue line shows the location of current during a properly timed pulse to give maximum acceleration. 


\section{Cradle Design and Fabrication by Nick Patz}

Using ANSYS to iterate the resulting stress and deflection of multiple thickness parameters and the resulting mass yielded a final cradle design. Figure 4 shows the front view of the final cradle excluding magnets resting on an aluminum support structure. The final material allocated for the inner support structure was XN-70/RS-12 high modulus cyanate unidirectional prepreg produced by YLA of Benicia. Two panels were laid up one of dimensions 12X26 inches and another of 18X26 inches. Both panels were autoclave cured at $250^{\circ} \mathrm{F}$ and postcured at $350^{\circ} \mathrm{F}$ then cut into five panels to create the inner surface of the sandwich structure of the cradle. The next step of the cradle fabrication is to machine the aluminum brackets that bond the previously mentioned five carbon fiber panels together and the machining of an aluminum support structure, a jig, to be used as a basic mold for precise bonding and support. The aluminum will be bonded to the carbon fiber with RS-15 a low viscosity epoxy resin also produced by YLA. It will be cured at $200^{\circ} \mathrm{F}$ on the jig while surrounded by vacuum. The expected completion of the bonding between aluminum and carbon fiber is August $22^{\text {th }}$.

The proceeding step in the cradle construction will be the mounting of the core and outer layer of the sandwich structure. The core will be composed of a combination of high modulus carbon fiber honeycomb core and foam core. It will be bonded to the bottom of the sandwich structure using a surfacing film. The upper surface of the sandwich structure will also consist of XN-70/RS-12 and will be bonded to the core materials using the same surfacing film. Both the sandwich structure layer and the surfacing film will be cured simultaneously at $250^{\circ} \mathrm{F}$ under constant vacuum.

Due to the directionally dependent thermal contraction coefficients of carbon fiber prepreg an analysis was preformed to determine the bowing effect of the outer ply of the sandwich structure. It was determined that the bottom of the cradle will bow outward approximately $0.2 \mathrm{~mm}$ which will be compensated for by shimming the construction of the bottom cradle panel to an equal distance in a opposite direction. The compensation will induce a negligible stress in the cradle and will yield the desired shape. 


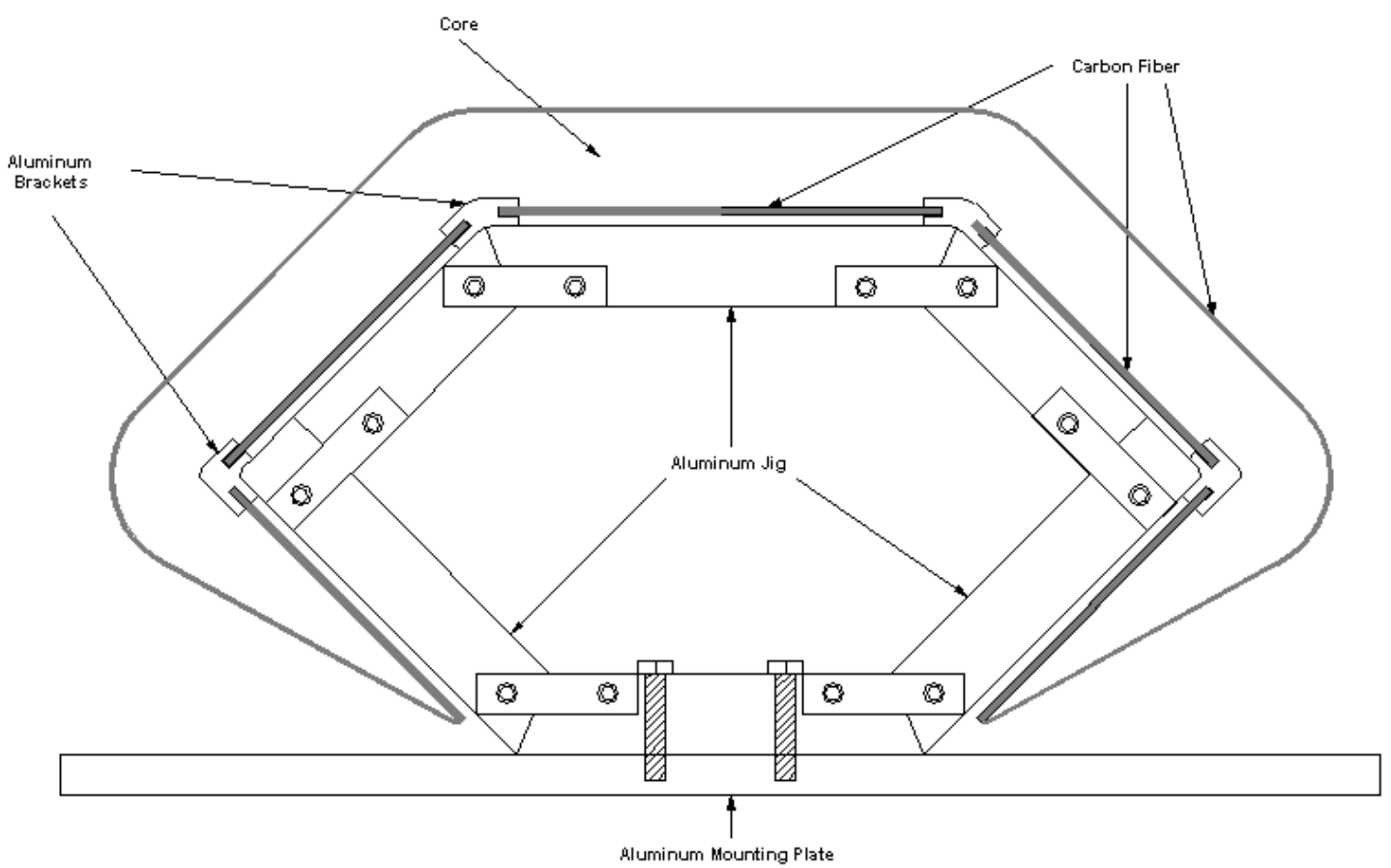

Figure 4. Front view of final cradle design mounted on aluminum support structure.

\section{Louann Tung}

Project manager

With input from team members Joel Martinez-Frias, Bill Kent, Nick Patz, and Brian Smith.

$8 / 13 / 99$ 


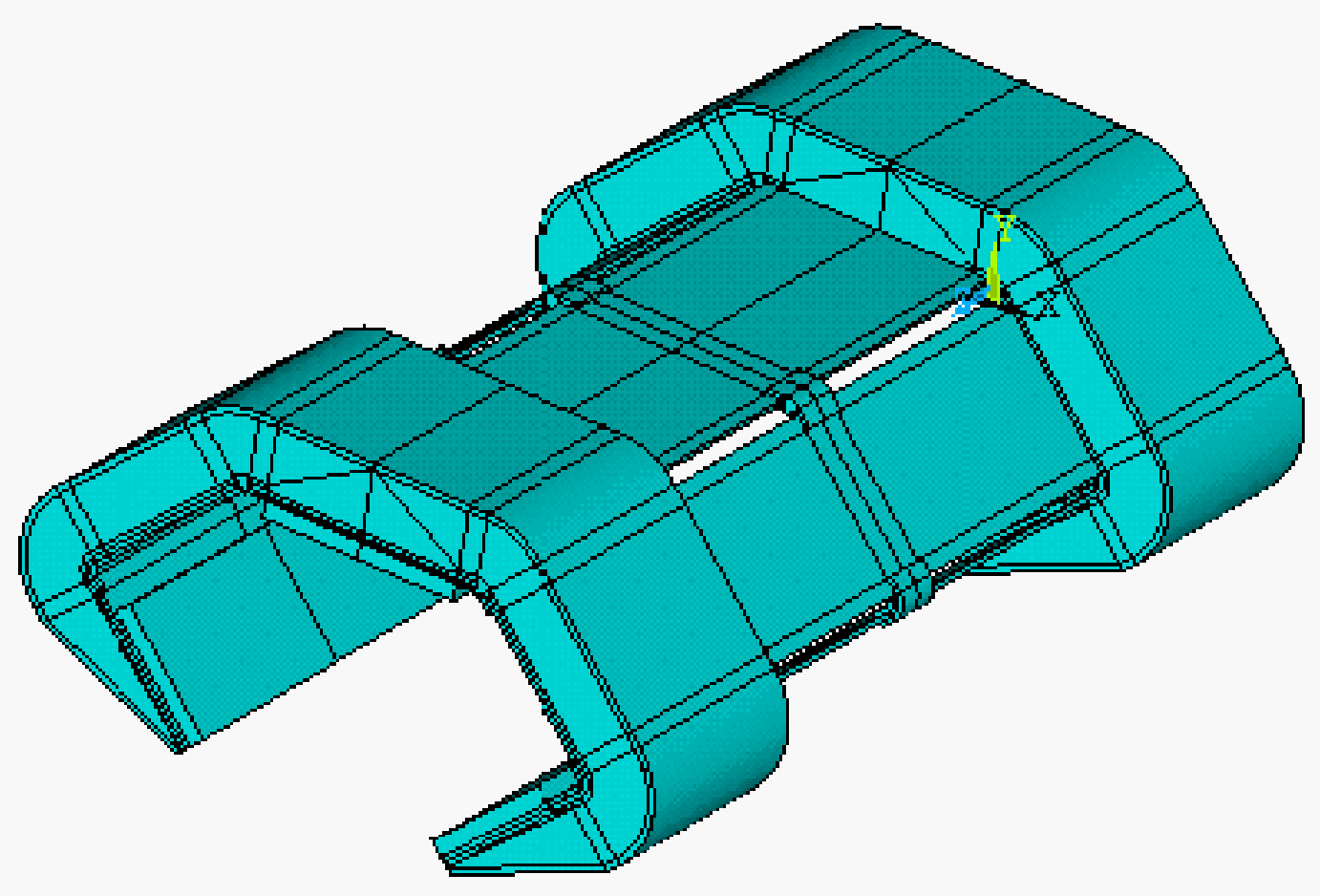

Figure 1. Carbon fiber composite design for the cradle using ANSYS.

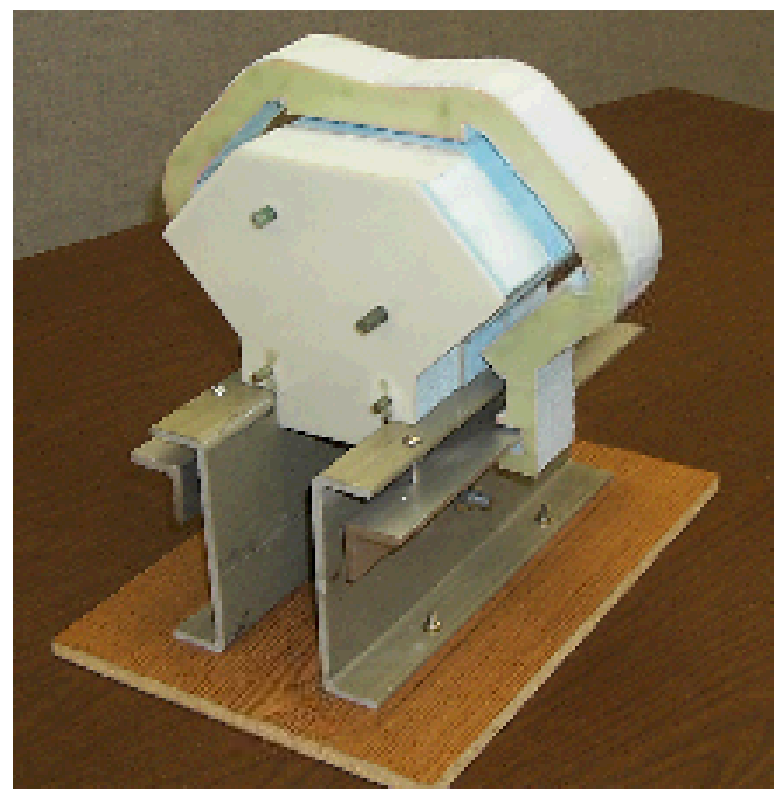

Figure 2. Photo of model of drive and levitation coil assembly. Note how the C-shaped teflon guide and rail will prevent the cradle magnets from touching the track prior to levitation 


\section{LLNL Inductrack Progress Report: August 15 - Sept. 15, 1999}

Financial: Expenditures in August were \$34,509.

\section{Accomplishments:}

\section{General}

- We have undergone a drastic change in the design of the electronic drive circuitry. The original design was to provide circuits connected to the 600 drive coils that each generated a pulse width of differing lengths to optimally accelerate the cradle down the track. This method resulted in the need for expensive switching components because 7000 Amps was provided to each drive coil in a pulse width of several hundred micro-seconds. After costing this design, we concluded that our budget could not afford this method. After some desparate and creative thinking, we arrived at a different approach. The new approach is to provide a constant pulse width throughout the acceleration. This eliminated the costly IGBT switches. (This method saved at least $\$ 60,000$.) An analysis was done with this scenario and we found that the cradle can be accelerated up to about $54 \mathrm{~m} / \mathrm{s}$ in 20 meters with one set of circuitry that provides a pulse width of 600 micro-sec. This assumes that an initial kick up to $10 \mathrm{~m} / \mathrm{s}$ can be provided mechanically. The C-fiber cradle plus the magnets weigh 8.5 $\mathrm{kg}$. The design is modular so that, as more funding is available, another section of circuitry can be added that can drive the cradle to greater speeds.

- The drive circuit has been designed and an order has been placed with DHN Ind. for 24 Dual SCR Trigger Cards. The cost is $\$ 4,300$ and arrival time is around Nov. 15 (a ten-week lead time). Thyristors for the drive circuit have been donated from another program at LLNL. An order for the thyristor assembly hardware has been place with VEP Inc. at a cost of \$2057 and the delivery date is Sept. 27.

- We are awaiting estimates from Custom Coil and MEI regarding the manufacturing of the drive coil and levitation coil assemblies. We have been changing the drive coil design by providing larger radii to reduce manufacturing labor costs. We are trying to get the costs below $\$ 50$ each for the drive (and compensation) coil (1-cm long) and $\$ 20$ for each 4-cm section of levitation coil. For an acceleration length of 20 meters, then we need 400 each of these at a total cost of $\$ 28,000$. (Our design of several months ago with the flat $\mathrm{Cu}$ strips would have cost over $\$ 200$ each!!) It is anticipated that the lead time for this will also be 8-10 weeks - THE ARRIVAL OF THESE COILS WILL LIKELY BE THE ITEM THAT AFFECTS THE CRITICAL PATH AND DELAY OUR PROGRESS.

- About 500 slow bank capacitors were donated from another program at LLNL. These have been reconditioned and tested (by our summer student Brian Smith). So we have about $25 \%$ extra if needed.

- A rectifier and transformer (worth about $\$ 10,000$ ) has been donated from another LLNL program that has no further use for these. Plant operations will install this equipment sometime in early November for a cost of about $\$ 5000$. This will avoid having to purchase additional slow capacitors needed to charge the fast bank.(See discussion below by Dan Shimer regarding the drive coil circuitry.)

- Magnets from Ugimag are now expected to arrive in late Sept. Delays occurred because of the shortage of personnel at Ugimag to measure the magnets prior to 
shipping. Apparently the magnets are already assembled and are awaiting measurement.

- The carbon-fiber cradle has been fabricated by our summer student Nick Patz. He fabricated this cradle at YLA - a C-fiber composite company in Benicia CA. YLA donated the material for this project and allowed Nick to use their facility. It has been estimated that the cost of this cradle (assembled from scrap satellite components) could roughly be $\$ 10,000$. (Nick's report on the assembly method is included in a separate report entitled "Carbon Fiber Cradle Fabrication".) A photo of the cradle (named "Darth") is shown in Fig. 1.

- We also are considering the possibility of Nick analyzing and measuring the stability the Inductrack cradle as a topic for his thesis in physics at Cal Poly in San Luis Obispo, CA.

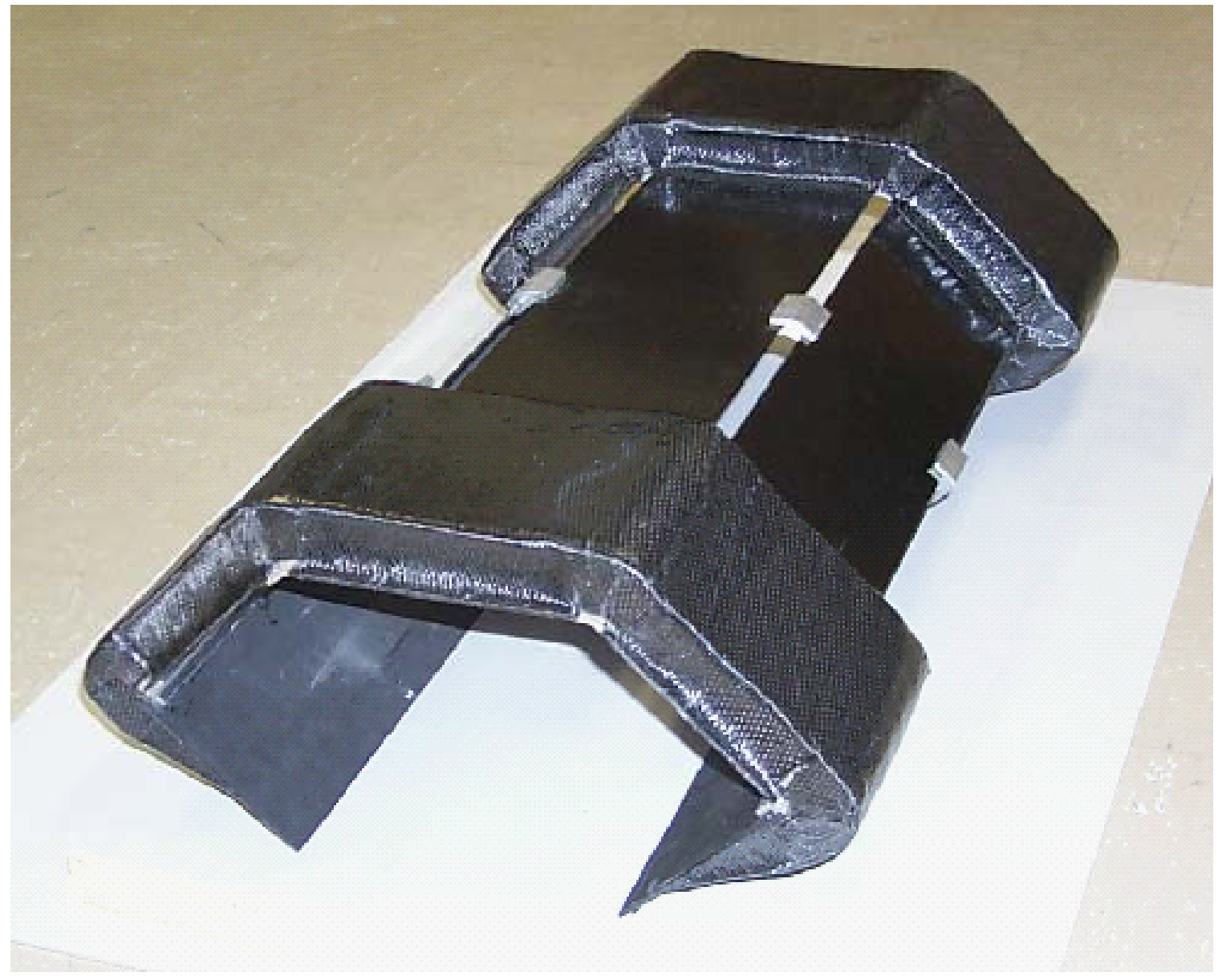


Figure 1. Carbon-fiber cradle completed by Nick Patz on Sept. 2, 1999. 


\section{Drive circuit design by Dan Shimer}

The drive coil design using \#6 square insulated magnet wire has been discussed with a coil fabrication vendor. Suggestions, such as increasing the bend radius, are being incorporated to reduce the cost.

Major changes in the drive circuitry were made to reduce complexity and cost. The two thyristors previously used as an ac switch for each group of drive coils were reconfigured to become a series inverter. This eliminates the need for expensive charging supplies for the resonant capacitors. When triggered, the series inverter both energizes the desired group of coils and creates a half-sine wave pulse of fixed amplitude and time. The pulse width and amplitude depend on the inductance and resistance of the coils, the capacitance of the resonant capacitor, and the dc bus voltage. The pulse width can be varied in discrete intervals along the track by changing the value of the resonant capacitor.

For the initial experiments the track will be powered for up to $20 \mathrm{~m}$. A maximum speed of 45 to $50 \mathrm{~m} / \mathrm{s}$ can be achieved with a drive current amplitude of $7000 \mathrm{~A}$ and a fixed pulse width of 600 microseconds. Figure 2 shows a schematic of the power circuitry. An isolation transformer and controlled ac-dc rectifier are used to create an unregulated $+/-300 \mathrm{Vdc}$ power supply for the drive circuits. It will be capable of providing up to $800 \mathrm{~kW}$ of power for up to one second. One set of resonant capacitors is used for all the circuits because the pulse width is constant for this range of track.

The drive coils will be connected in series electrically in groups of 13 . This results in 24 circuits for the 15.6-m track. Two adjacent circuits will be energized simultaneously depending on the vehicle position along the track. Because the vehicle spans 13 coils, the coils interacting with the front and rear magnets will always be energized. Optical sensors will detect the vehicle position and control turn-on of the particular thyristor circuits. Design for these sensors is in progress. 


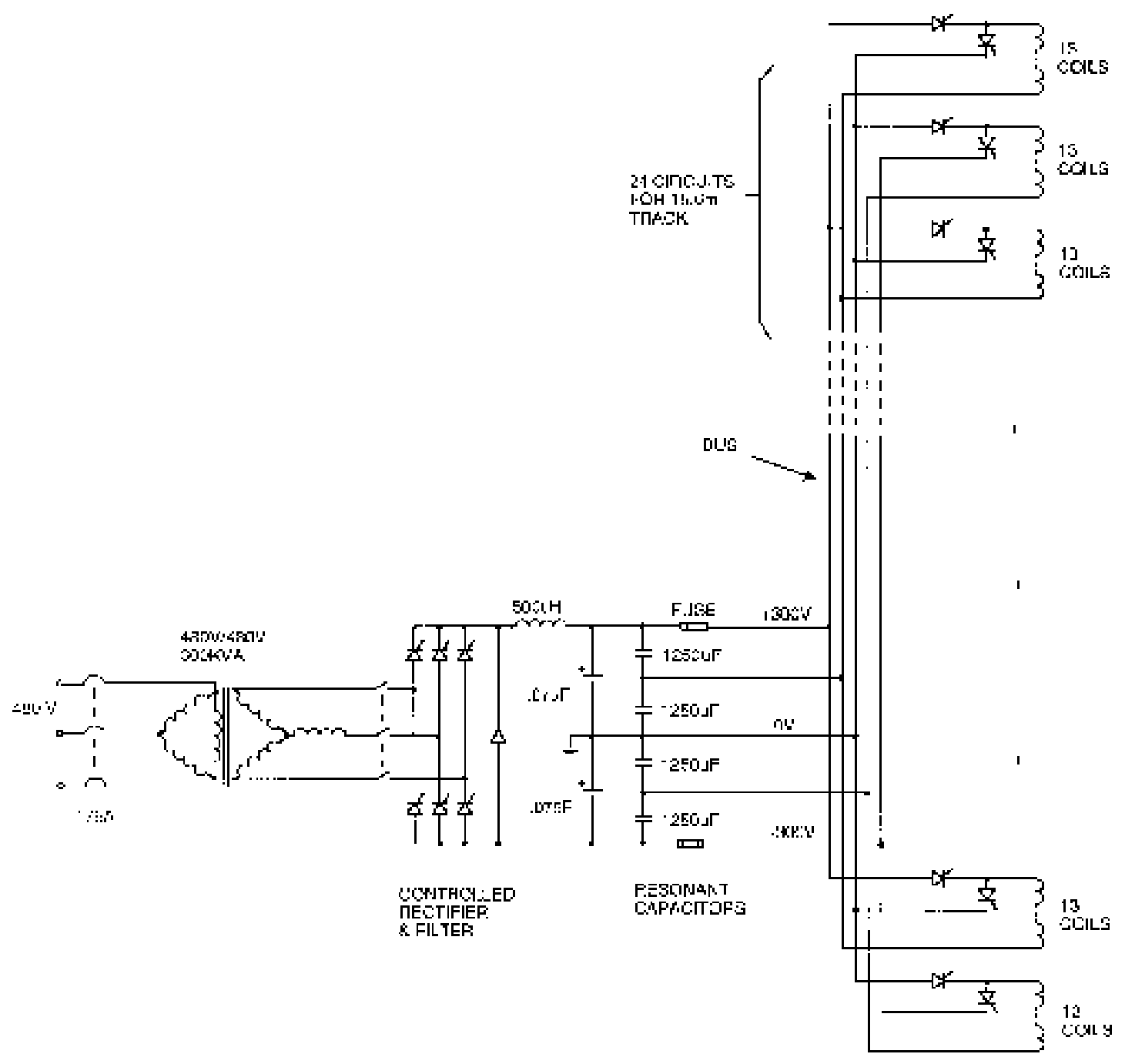

Figure 2. Power circuit for 15.6-m track using series inverters. 


\section{CARBON FIBER CRADLE FABRICATION by Nick Patz}

\section{$\underline{\text { Design }}$}

- Prior to the carbon fiber design an aluminum cradle design already existed. It weighed approximately $11 \mathrm{~kg}$ with magnets.

- The constraints on the cradle were of two parts.

Maximum deflection of $0.25 \mathrm{~mm}$.

Withstand loading at max velocity of $295 \mathrm{~N}$.

- Carbon fiber was chosen to yield the same strength while decreasing the weight.

- Benefits of carbon fiber.

High modulus, and strength.

Low density.

High thermal conductivity.

- Weaknesses of carbon fiber.

Orthotropic properties.

Small plastic region during deformation.

Specialized equipment required for construction. 
F.E.A.

- The carbon fiber cradle design was analyzed using a multiple parameter based ANSYS, F.E.A. program.

- ANSYS can analyze materials with orthotropic properties but to simplify the design a spreadsheet was created to convert a multidirectional composite laminate into a single material of orthotropic properties.

The Excel spreadsheet to analyze resulting properties.

\begin{tabular}{|c|c|c|}
\hline $\begin{array}{l}\text { Input } \\
\text { Ep oxy/T3 }\end{array}$ & & \\
\hline $\mathrm{E}_{1(\mathrm{Gpa})}$ & 153 & \\
\hline E2(Gpa) & 11.2 & \\
\hline$v 12$ & 0.28 & \\
\hline $\mathrm{G}_{12(\mathrm{Gpa})}$ & 7.1 & \\
\hline$\rho(g / c c)$ & 1.55 & $t(m)$ \\
\hline$\theta 1$ & 0 & 0.0053 \\
\hline$\theta 2$ & 0.78539816 & 0.0053 \\
\hline$\theta 3$ & -0.78539816 & 0.0053 \\
\hline$\theta 4$ & 1.57079633 & 0.0053 \\
\hline$\theta 5$ & 0.78539816 & 0.0053 \\
\hline$\theta 6$ & -0.78539816 & 0 \\
\hline$\theta 7$ & 0 & 0 \\
\hline$\theta 8$ & 0 & 0 \\
\hline$\theta 9$ & 0 & 0 \\
\hline$\theta 10$ & 0 & 0 \\
\hline
\end{tabular}

\begin{tabular}{|c|c|c|c|c|c|}
\hline$\underline{\mathrm{C}} 11$ & $\underline{\mathrm{C}} 12$ & $\underline{\mathrm{C}} 22$ & $\underline{\mathrm{C}} 16$ & $\underline{\mathrm{C}} 26$ & $\underline{\mathrm{C}} 66$ \\
\hline 153.883148 & 3.15410166 & 11.26464878 & 0 & 0 & 7.1 \\
\hline 49.9640001 & 35.7640001 & 49.96400014 & 0 & 35.65462492 & 39.7098985 \\
\hline 49.9640001 & 35.7640001 & 49.96400014 & 0 & -35.6546249 & 39.7098985 \\
\hline 11.2646488 & 3.15410166 & 153.8831485 & $3.72859 \mathrm{E}-16$ & $8.35972 \mathrm{E}-15$ & 7.1 \\
\hline 49.9640001 & 35.7640001 & 49.96400014 & 0 & 35.65462492 & 39.7098985 \\
\hline 49.9640001 & 35.7640001 & 49.96400014 & 0 & -35.6546249 & 39.7098985 \\
\hline 153.883148 & 3.15410166 & 11.26464878 & 0 & 0 & 7.1 \\
\hline 153.883148 & 3.15410166 & 11.26464878 & 0 & 0 & 7.1 \\
\hline 153.883148 & 3.15410166 & 11.26464878 & 0 & 0 & 7.1 \\
\hline 153.883148 & 3.15410166 & 11.26464878 & 0 & 0 & 7.1 \\
\hline
\end{tabular}

\begin{tabular}{|l|r|}
\hline $\mathrm{v} 21$ & 0.02049673 \\
\hline C11 & 153.883148 \\
\hline C12 & 3.15410166 \\
\hline C22 & 11.2646488 \\
\hline C66 & 7.1 \\
\hline
\end{tabular}

\begin{tabular}{|c|c|c|c|c|c|c|}
\hline$\Delta$ & $\underline{\mathrm{C}} 11 \mathrm{~g}$ & $\underline{\mathrm{C}} 12 \mathrm{~g}$ & $\underline{\mathrm{C}} 22 \mathrm{~g}$ & $\underline{\mathrm{C}} 16 \mathrm{~g}$ & $\underline{\mathrm{C}} 26 \mathrm{~g}$ & $\underline{\underline{\mathrm{C}} 66 \mathrm{~g}}$ \\
\hline 88894.9323 & 63.0079595 & 22.7200407 & 63.00795953 & $7.45718 \mathrm{E}-17$ & 7.130924984 & 26.6659391 \\
\hline
\end{tabular}

Re sults
\begin{tabular}{|l|c|}
\hline Ex(Gpa $)$ & 54.560 \\
\hline Ey(Gpa) & 52.908 \\
\hline Gxy(Gpa & 25.738 \\
\hline vxy & 0.372 \\
\hline vyx & 0.361 \\
\hline
\end{tabular}


- Two weeks were required to set up and iterate the model. The end result was a structure that meets the required loads and deflection.

$>\quad$ The bottom sandwich structure consists of five separate 0 /90 balanced panels of the same thickness $3 \mathrm{~mm}$ and a length of $64 \mathrm{~cm}$

$>\quad$ The core was chosen as a minimum strength component.

$>\quad$ The upper sandwich structure consists of only 0 unidirectional prepreg.

- The final cradle design consisted of five separate materials

$>\quad$ Aluminum brackets

$>\quad$ Balteck H-900 foam core

$>\quad$ 106-glass/RS-9 low dielectric honeycomb core.

$>\quad$ M40J/RS-1 unidirectional prepreg.

$>\quad$ Tensile strength $\quad 2027 \mathrm{Mpa}$

$>\quad$ Tensile modulus $207 \mathrm{Gpa}$

$>\quad$ Compression strength $1174 \mathrm{Mpa}$

$>\quad$ Compression modulus $205 \mathrm{Gpa}$

D XN-70A/RS-12 unidirectional prepreg.

$>\quad$ Tensile strength $2033 \mathrm{Mpa}$

$>\quad$ Tensile modulus $\quad 428 \mathrm{Gpa}$

$>\quad$ Compression strength $590 \mathrm{Mpa}$

$>\quad$ Compression modulus $383 \mathrm{Gpa}$ 
- The first step in the construction of the cradle was the five High modulus XN-70/RS12 panels. Two panels, one $1.5 \mathrm{ft}$ X $2 \mathrm{ft}$ and the other $1 \mathrm{ft} \mathrm{X} 2 \mathrm{ft}$ were laid up 34 plies thick alternating 0 then 90 for 17 plies then mirrored on the opposing side.

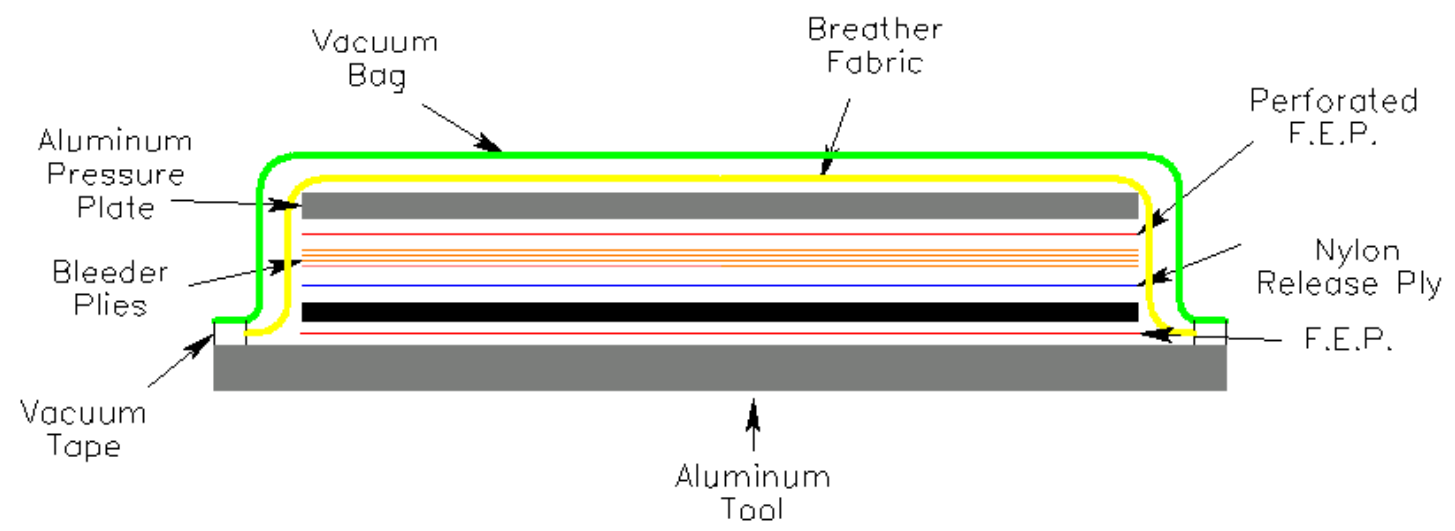


- Aluminum brackets were designed and fabricated on site. An aluminum jig was also designed and constructed to support the cradle during the curing and bonding steps of its fabrication.

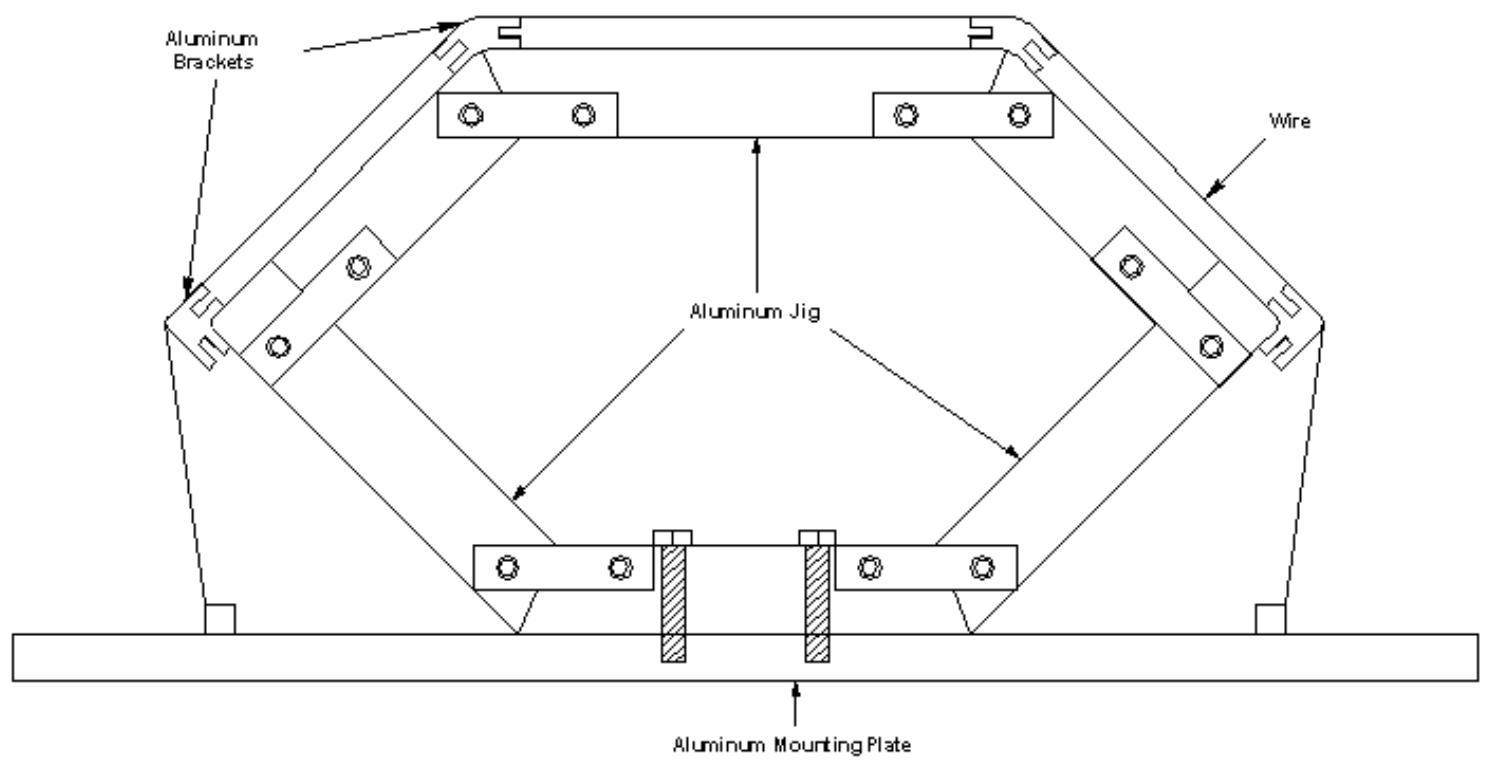


- The bagging procedure for the cradle was to be in two parts. The first was to de bulk the laminate.

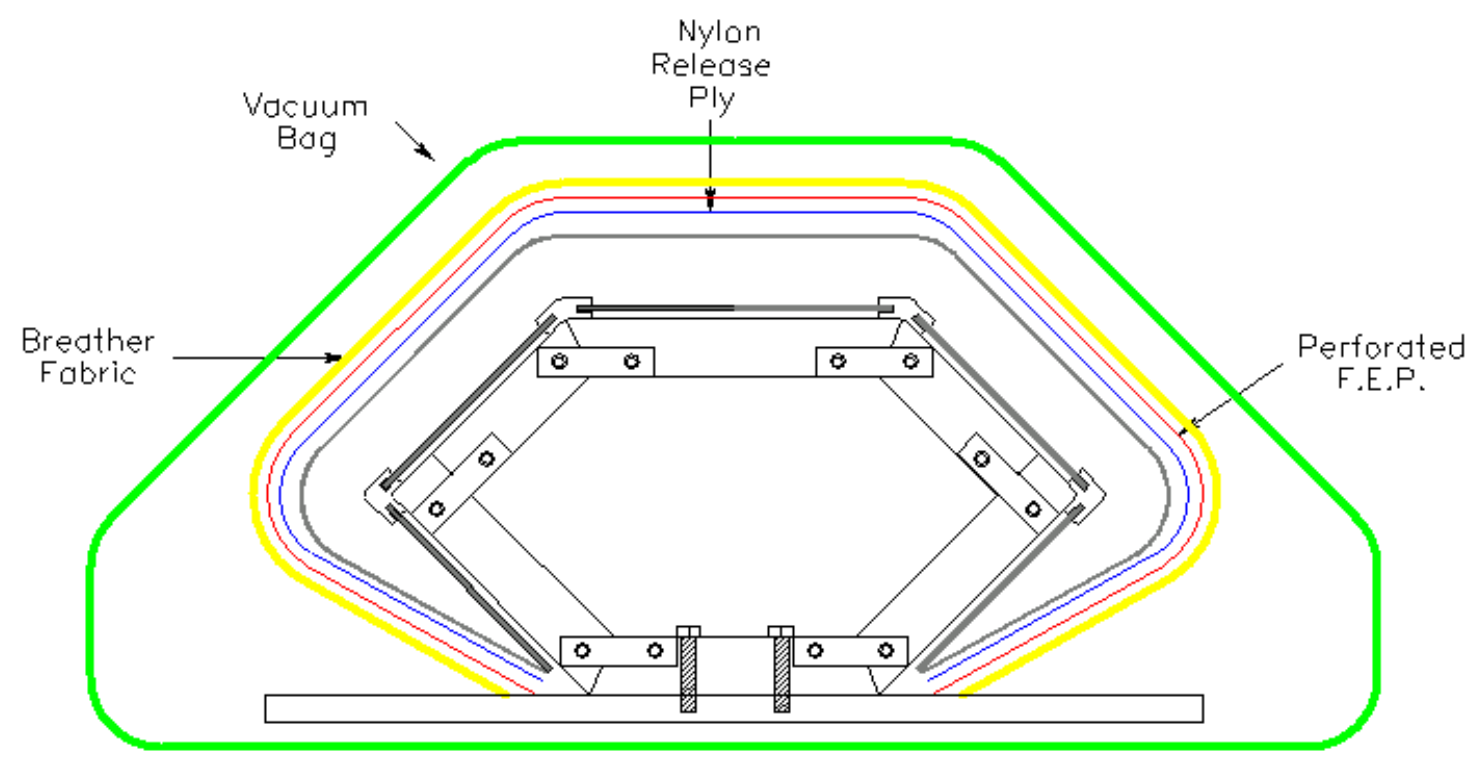

- The second step is to create a smooth surface on the outside of the sandwich structure.

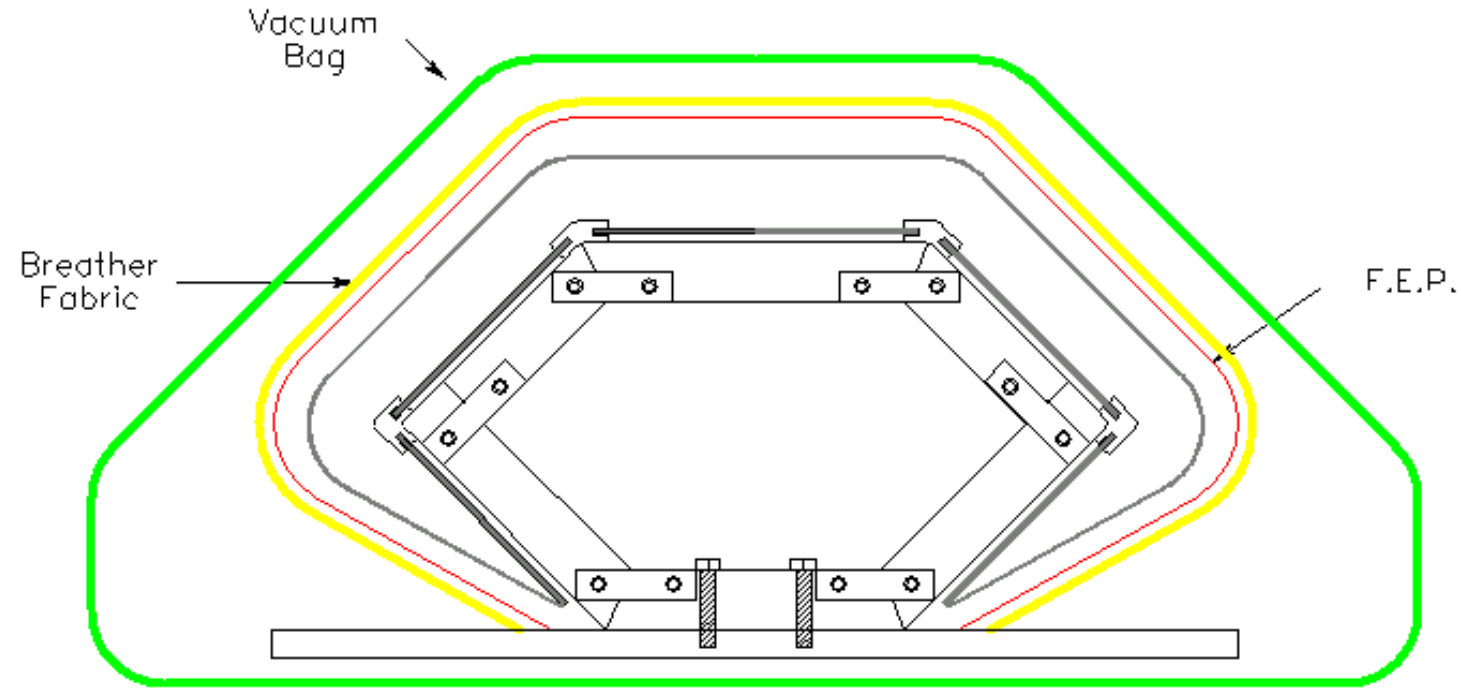




\section{End Results}

- The cradle is structurally sound but cosmetically inferior than designed.

- The final weight of the cradle will be $8.5 \mathrm{Kg}$ as predicted. The resulting benefit in terms of a velocity analysis is as follows.

- For a $11 \mathrm{Kg}$ cradle the velocity with a pulse width of $600 \mu \mathrm{s}$ at the end of $20 \mathrm{~m}$ is $46 \mathrm{~m} / \mathrm{s}$. The $8.5 \mathrm{Kg}$ cradle has a velocity of $54 \mathrm{~m} / \mathrm{s}$ at the same distance.

\section{$\underline{\text { Possible Future Modifications }}$}

- Removal of honeycomb core in replacement of foam core.

- Modification of aluminum jig.

- Higher modulus outer sandwich structure. 


\section{LLNL Inductrack Progress Report: Sept. 15 - Oct. 15, 1999}

Financial: Expenditures in September were $\$ 15,000$.

\section{Accomplishments:}

\section{General}

- Dick Post presented a talk and a paper at the IEEE conference on magnetics in Florida last month. His paper which is the first published paper on the passive mag lev concept is included in the email with the present report.

- Dick Post and Louann Tung will attend the $5^{\text {th }}$ International Symposium on Magnetic Suspension Technology sponsored by NASA Langley, held at Santa Barbara, CA on Dec. 1-3. Our division management has agreed to paying our labor costs to attend and the costs of the conference, hotel, and per diem. (So costs will not be taken from the Inductrack 2000 budget.)

- We disassembled the first Inductrack experiment in 3-foot sections, removed it from the building and placed it in a transportainer. (Another directorate took over the building Oct. 1 which became our move-out deadline.) Until the Inductrack 2000 is assembled, at present there is no demonstration experiment for the Inductrack concept.

\section{Mechanical}

- The six magnet arrays and a spare set have arrived. Half of the magnets appear to have good alignment to each other. The other half have off-sets less than 1/32". After an initial inspection, in the worse array, the epoxy holding the end bar in gave way while in storage. We are in the process of attaining the assembly fixture and the type of epoxy used by Ugimag so that we can repair the arrays ourselves. Ugimag also said that during field measurements on the arrays, that one array broke. We were cautioned to have great care in handling these arrays of 5 magnets bars which are epoxied only between the bars. We are still awaiting the information from Ugimag confirming the measurement of the field strength of each array. The cost of the 12 arrays (60 magnets) was $\$ 8500$.

- A design for kicker that uses compressed air has been conceptualized. The purpose of the kicker is to provide mechanical acceleration of the cradle for the first meter up to $10 \mathrm{~m} / \mathrm{s}$. Mechanical acceleration at the low speed is more cost effective than using electrical drive.

\section{Electrical}

- The design for the trigger circuitry has been done. The sensing of the cradle position will be accomplished by emitter/detector pairs for infrared sensing. About 100 pairs (\$25 each) will be placed along the side of the track. The cradle will have an aluminum bracket that extends down to the track. This light-weight bracket will have wide teeth that will pass between these sensors in order to break the infrared transmission when the magnets on the cradle align with the drive coil to be triggered. This signal will also be used as a measure of cradle velocity.

- We are still awaiting estimates from Custom Coil and MEI regarding the manufacturing of the drive coil and levitation coil assemblies. We have undergone the final review of the design and will be visiting the vendors within the next week. Our 
rough estimate for 15 meters of drive/levitation coils is $\$ 40,000$. Other vendors will be brought in if this cannot be accomplished otherwise the track length will have to been shorted to a length that we can afford. 


\section{Cost update}

An estimate of the costs remaining (starting Oct.1 and ending Jan. 31) shows the following:

1. Mechanical: magnets, track hardware, and kicker. Total $=\$ 14,100$

2. Electrical: drive/lev coils (15 meters), drive circuit boards, thyristors, power distribution to drive coils, insulation, bus bar, high-current lugs and connectors, fuses, trigger sensors, eddy current decelerator, labor to assemble components and install transformer and rectifier. Total $=\$ 82,100$

3. Labor for mechanical and electrical technician and for experiment acquisition and analysis $=\$ 58,350$ (This assumes our technicians only work half-time in order to balance the budget - if they were to work at the effort needed then the labor costs would be $\$ 82,300$ ) 


\section{LLNL Inductrack Progress Report: Oct. 15 - Nov. 15, 1999}

Financial: Expenditures in October were \$52,074.

\section{Accomplishments:}

\section{General}

- Dick Post and Louann Tung will attend the $5^{\text {th }}$ International Symposium on Magnetic Suspension Technology sponsored by NASA Langley, held at Santa Barbara, CA on Dec. 1-3. A paper was written for this conference and is included in the email with the present report. (It has been reviewed and released for public distribution.) (Conference web site at http://www.engineering.ucsb.edu/ p paden/ISMST/ISMSTframes.html )

- We are preparing a presentation for 5 visitors from NASA Dryden (organized by Kurt Kloesel) which is scheduled to be on Nov. 22.

- We originally had discussions with Custom Coil regarding the manufacturing of our drive and levitation coils. Recall that the drive coils have undergone several design changes in order to get the cost per coil to a reasonable number - this is the component that is causing the schedule to slip. It turns out that Custom Coil cannot produce our coils in the time frame needed. Consequently we sent drawings (similar to those shown below) to 22 different coil vendors. Four bids were within our budget. The best candidate is MEI in Oakland CA who we are in final negotiations with.

\section{They are available to start immediately and can do the work within 4-6 weeks.} We visited their facility and found their quality of work to be quite good and consistent with recommendations of other LLNL employees. MEI has manufactured magnet coils for LLNL, LBNL, SLAC, and NRL. The cost for the entire 16 meters of drive and levitation coils (provided in 24 sections that are $65 \mathrm{~cm}$ long) will be less than $\$ 30,000$. This value falls within our budget.

- The following items have been ordered at a total cost of $\$ 21,000$ : circuit boards, thyristor hardware, track power distribution, copper bus bars, capacitor brackets, fuses, filter capacitors, cable with lugs, and insulated tape. Most of these components have arrived and are awaiting assembly.

\section{Electrical}

- Detailed design drawings have been produced to show all of the power wiring to the track line in order to facilitate fabrication of the circuit components along the track. Schematics have also been made for the four resonant capacitor banks. In progress are drawings for the filter capacitor banks (to condition the rectifier output), the thryistor switching assemblies, and the fuse and terminal block cabinets.

- Presently ac input power to the rectifier power supply is being installed. This rectifier will provide the pulse power to drive the cradle down the track. With an estimated value of about $\$ 10,000$ this rectifier is being borrowed (under a long term loan) from another LLNL program that is presently shutdown. Electrical switch gear and cabling has also been provide free of charge from this program. We estimate that this has saved our project about $\$ 70,000$.

Mechanical

- LCW supply was brought in to provide cooling to the rectifier.

- Mechanical support was added to equipment in the lab to meet earthquake code requirements. 
- Drawings were made to send to vendors as shown in Figs. 1-4.

Louann Tung: Project Manager

With input from team members Bill Kent and Ernie Schwarz. 

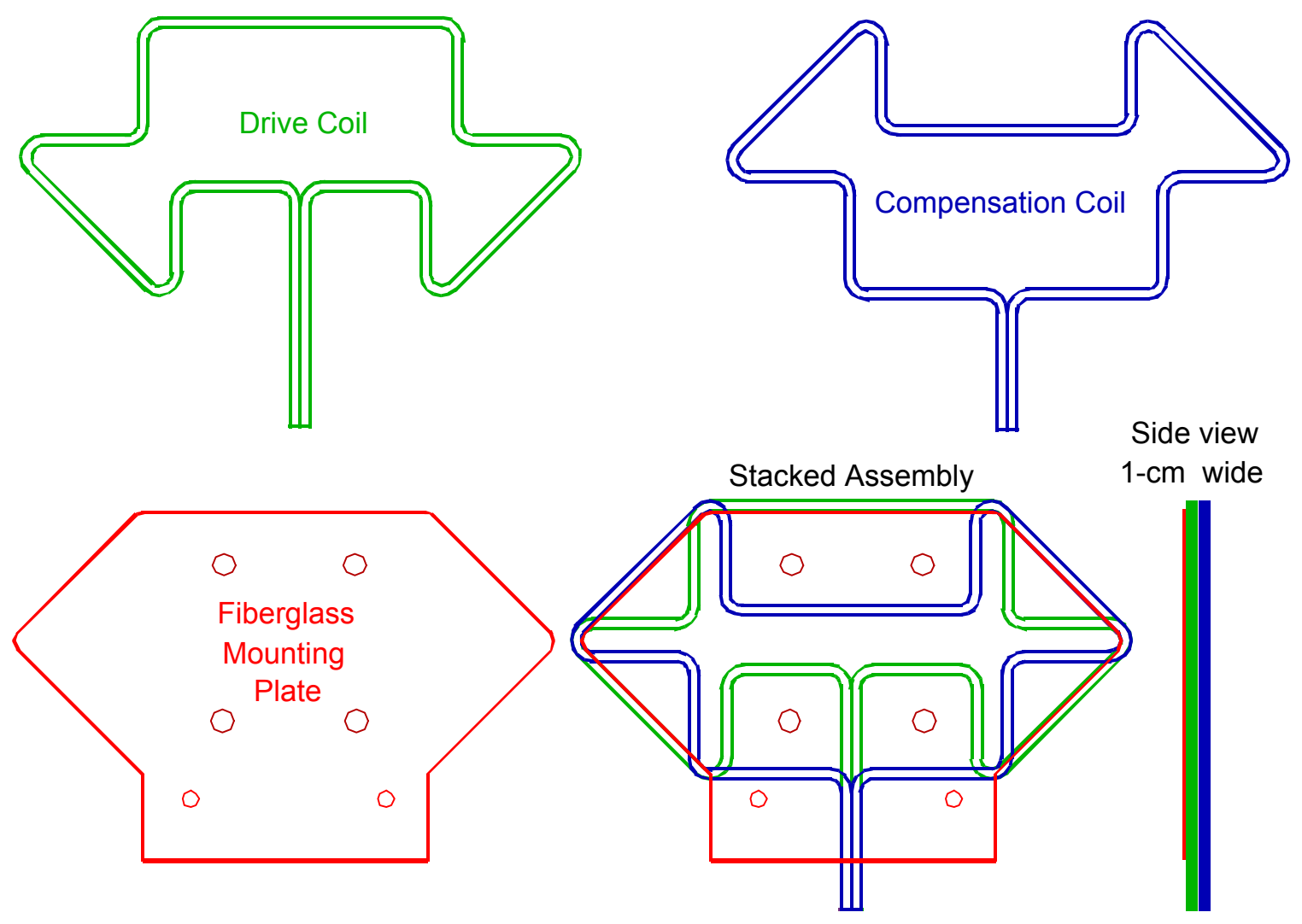

FIGURE 1. Drive coil assembly is composed of a drive coil, compensating coil (needed to zero the average magnetic field generated by the drive coil and minimize interference with the levitation coils), and mounting plate. The drive coil provides a 7000 Amp pulse that is 
$6 \times 10^{-4} \mathrm{sec}$ long to accelerate the cradle to $50 \mathrm{~m} / \mathrm{s}$ at the end of 16 meters of track.

\section{Levitation Coil \#10 Sq. Magnet Wire}

Single Layer 14 Turns

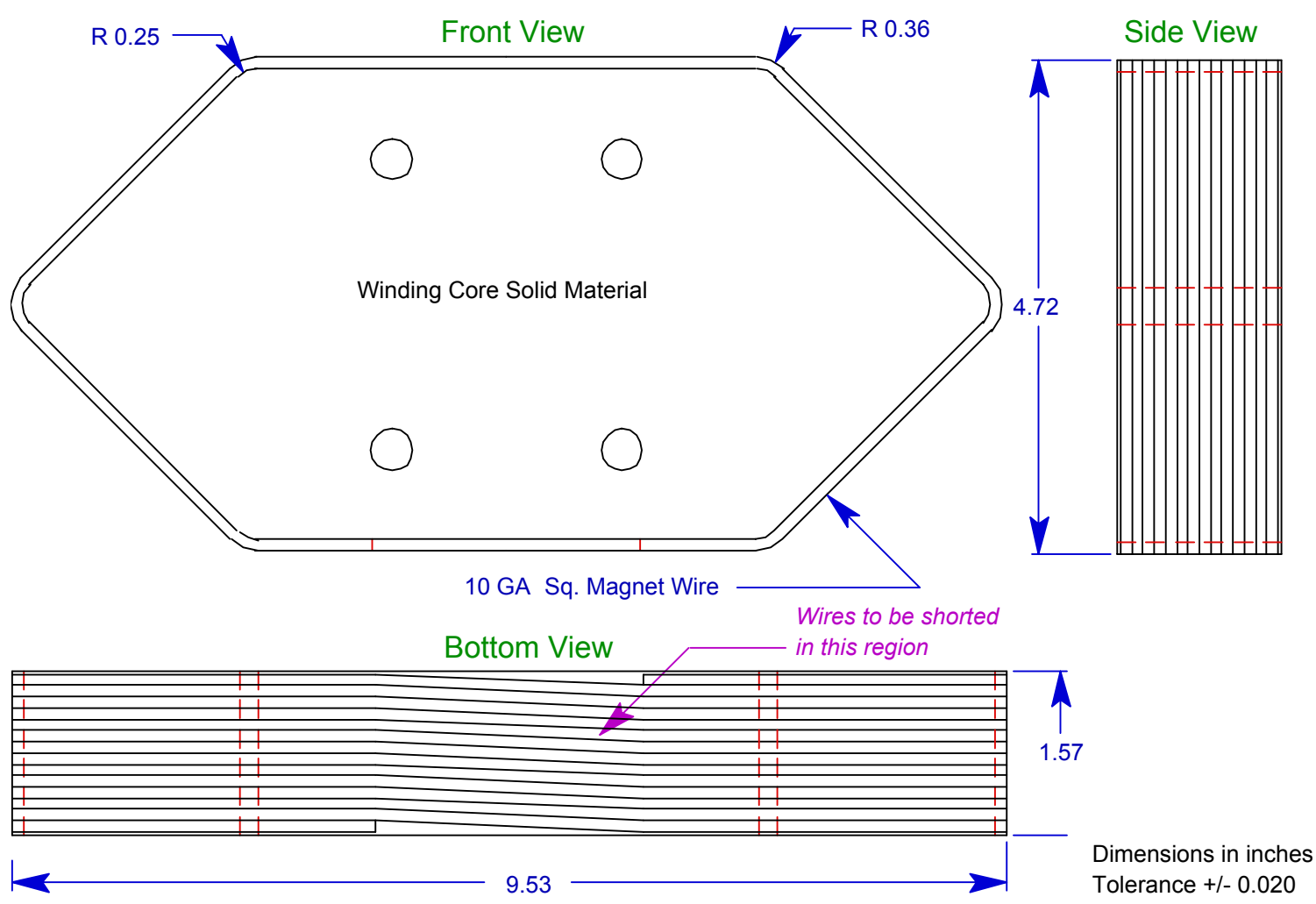

FIGURE 2. Detail of levitation coil composed of 14 turns of magnet wire that is shorted 


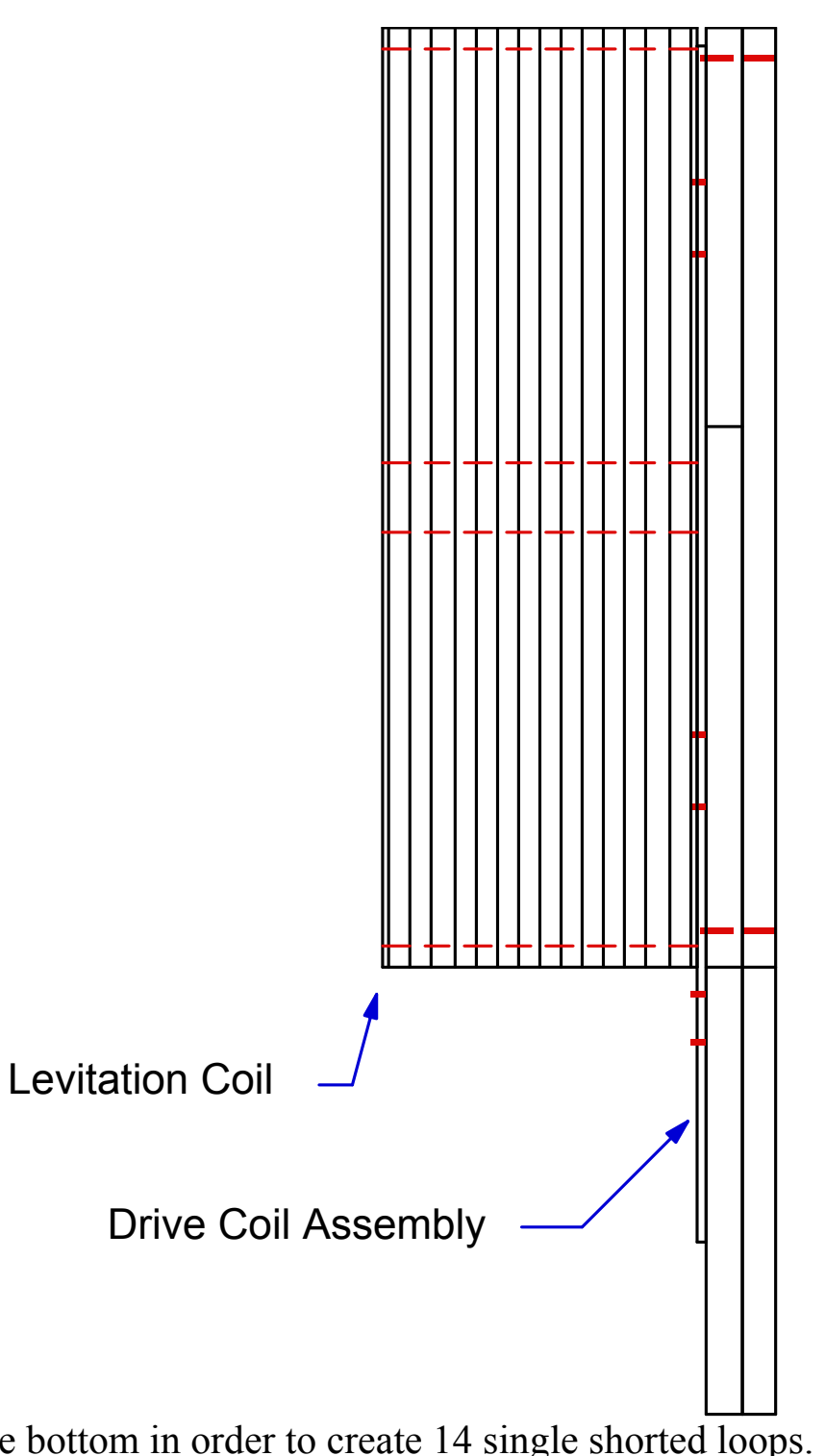

on the bottom in order to create 14 single shorted loops. 
FIGURE 3. Side view of levitation coil and drive coil assembly with a total width of 5-cm.
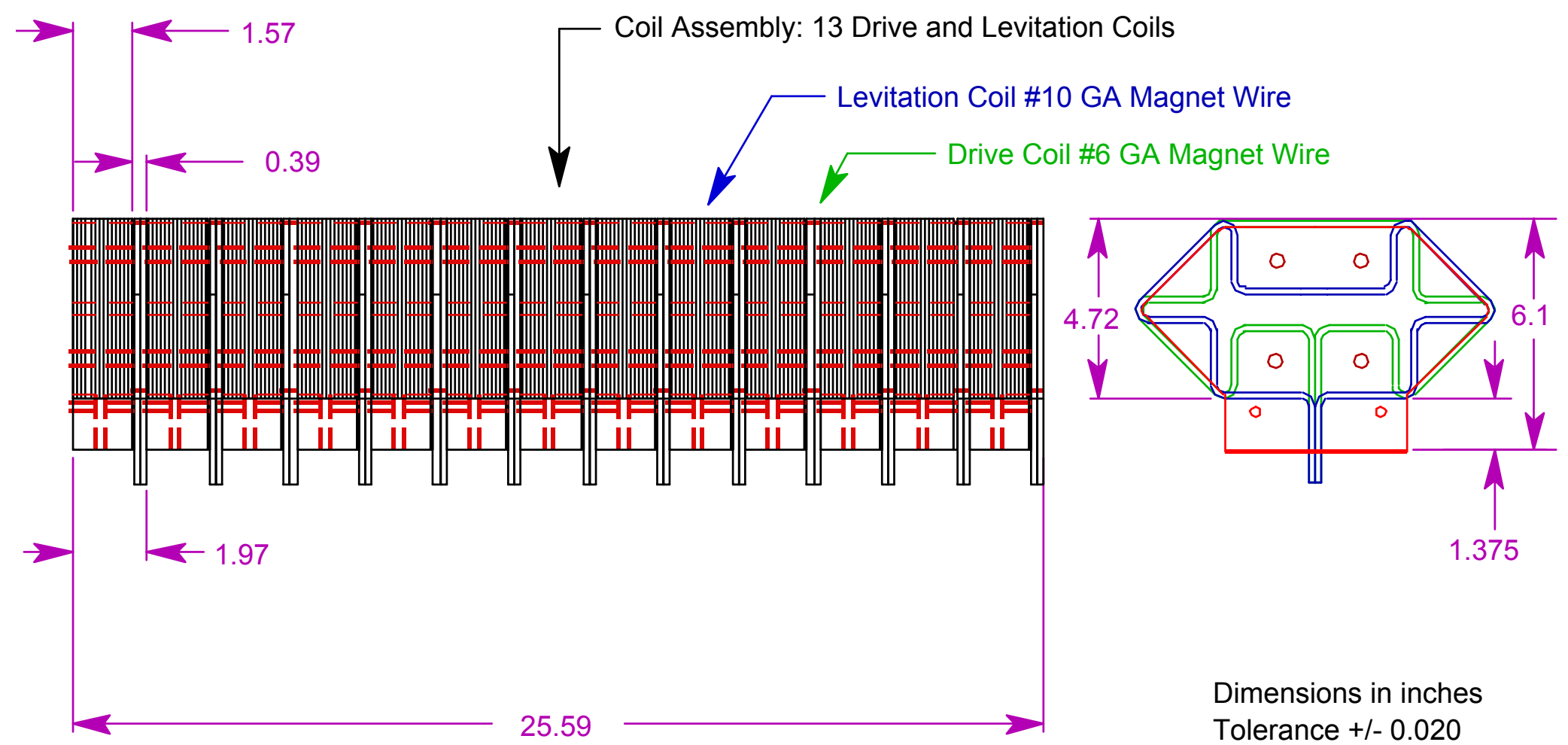

Dimensions in inches

Tolerance +/- 0.020 
FIGURE 4. A section of assembled drive and levitation coils. There are 24 of these sections to make up the 16-meter track. 


\title{
LLNL Inductrack Progress Report: Nov. 15 - Dec. 15, 1999
}

Financial: Expenditures in November were $\$ 50,902$.

\begin{abstract}
Status:
As discussed during a phone conversation between Louann Tung, Ray Smith, Bill Jacobs, and Roxanne Carter on Tues. Dec. 14, we cannot meet our Phase II goal by Jan. 31, 2000 with the present schedule and budget. For the reasons discussed in detail below, we are requesting additional funds to cover the labor needed to do the final assembly and testing to achieve the stable levitation and acceleration of the cradle to $50 \mathrm{~m} / \mathrm{s}$. By mid-January we plan to provide NASA MSFC details on the drive/levitation coil costs and the labor time and costs to finish assembly, conduct launch tests, and write a final report.
\end{abstract}

At the beginning of this past summer, it became painfully obvious that our initial drive coil design and drive circuitry configuration led to costs that were clearly not affordable. At mid-summer we had the good fortune that a senior PhD electrical engineer Dan Shimer joined our group for two months because of the shutdown of a previous LLNL program. Previous to this, we relied on another EE, who was committed $100 \%$ to other projects, to work on our Inductrack in his "spare" time - which led to painfully slow progress in this area. As documented in the July/August report, Dr. Shimer designed a new drive coil design and drive circuitry that we could afford. Consequently we believe that this new cost effective design will certainly make future Inductracks more affordable.

To recover the costs associated with the lost time of several months, we downscaled our goal to achieve $50 \mathrm{~m} / \mathrm{s}$ in Phase II. We estimate that the procurement costs are within our budget but find that we are several months behind in the assembly work and in purchasing the drive/ levitation coils. We are presently hiring a designer to make formal coil drawings, which should be completed by mid-January. These drawings will also provide clear documentation for future upgrades. However we are low on the priority list for designers because at the present time the National Ignition Facility here at LLNL has top priority. After the drawings are complete, we will go out for formal bids. This process should progress rapidly because we have already sent informal drawings to 23 vendors and found two in the area that were contenders. In fact the most likely contender MEI has been working with us to improve the drive coil shape to reduce fabrication costs. Costs for the 16-meter assembly of drive/levitation coils should be within $\$ 40 \mathrm{~K}$ and require about 6 weeks of lead time by the vendor.

When all the costs of procurement and labor are known by mid-January, we will provide the remaining cost estimates NASA so that we can finalize the additional costs needed to achieve our Phase II goals. At this time, we roughly estimate that an additional cost of $\$ 60 \mathrm{~K}$ to $\$ 100 \mathrm{~K}$ is needed for 3- months of assembly and testing. Thus pending this additional funding and time-extension of our Phase II contract, we plan to fly the cradle at $50 \mathrm{~m} / \mathrm{s}$ before the end of April. Also in January we will estimate what speed we can achieve with a drive section that is 2-3 times longer and is affordable under Phase III funds. 


\section{Accomplishments: \\ General}

- On Nov. 22, we hosted a day-long visit from engineers from NASA -Dryden. The original list included David Bushman, Vince Chacon, Kurt Kloesel, John Sharkey, Gregory Spencer (at the last minute one was replaced and one dropped out). We presented our present design and showed them the progress made on construction. We also arranged for a tour of nearby Trinity flywheel (www.trinityflywheel.com/ ). We believe that flywheel energy storage may solve the issues of pulsed power for a full -scale launcher. A detailed discussion on this is provided by Dick Post at the end of this report.

- Dick Post and Louann Tung attended the $5^{\text {th }}$ International Symposium on Magnetic Suspension Technology sponsored by NASA Langley, held at Santa Barbara, CA on Dec. 1-3. Louann presented the Inductrack concept and overview in a talk. The viewgraphs are attached in the email with this Nov/Dec report. At the conference, discussions were held with Kurt Kloesel from NASA Dryden and Jose PerezMorales, Ric Adams, and Robert Youngquist from NASA Kennedy.

\section{Mechanical}

- The following is a preliminary analysis of a mechanical launch system that will accelerate the cradle to $10 \mathrm{~m} / \mathrm{s}$ prior to reaching the active drive coil section.

Inductrack Start-up Propulsion System by Joel Martinez-Frias

The Inductrack magnetic levitation system requires motion of the cradle along the track for proper operation. However, the initial start-up motion of the cradle must be provided using an independent mechanism. The cradle must be accelerated to reach a velocity of $10 \mathrm{~m} / \mathrm{s}$ at the beginning of the track. We are proposing a spring propulsion mechanism to initially accelerate the cradle.

A spring, $3 \mathrm{~m}$ in length, $10 \mathrm{~cm}$ in diameter, would be compressed half its length to push the cradle. To reach a velocity of $10 \mathrm{~m} / \mathrm{s}$ after a displacement of $1.5 \mathrm{~m}$, an acceleration of $33.3 \mathrm{~m} / \mathrm{s}^{2}$ will be required. The spring should apply a force of $416.6 \mathrm{~N}$ to accelerate $12.5 \mathrm{~kg}$ (the $8.5-\mathrm{kg}$ cradle plus approximately $4.0 \mathrm{~kg}$ of the pushing device). A rigid shaft inside the spring will provide the mechanical support for the spring's extension. A trigger mechanism will secure the spring in its compressed condition until safely activated by the operator. A tube placed before the spring will run along the shaft when the spring is compressed and released. The tube will serve to support the plaque that will push the cradle along the track. A cable attached to the tube will allow the compression of the spring using a lever-pulley system.

The pushing device consists of an aluminum plaque about $23 \mathrm{~cm}$ high, $32 \mathrm{~cm}$ wide and $1 \mathrm{~cm}$ thick mounted over to the tube. The plaque will have a semicircular cut in its base where it will be welded to the tube. In addition, the plaque will hold high-density rubber pads whose geometric arrangement coincides exactly with the cross-section of the cradle. 
Once the tube is bulled back compressing the spring, the tube will be held in place by the trigger holding a wedge that is welded to the tube. The trigger consists of a twoarm lever whose arms form an angle of about $120^{\circ}$ degrees. The trigger itself is the lower arm of the lever, while the upper arm holds the wedge in place. The arms of the lever form a vertex where an axle supports the lever and allows it to rotate to release the wedge. 


\section{Studies of Optimized Pulsed-Power Systems for a Full-scale Maglauncher System by}

R. F. Post

In looking toward the construction of a full-scale Maglauncher system a major cost driver will be the cost of the pulsed-power electromagnetic drive system needed to accelerate the rocket and its launching cradle to full speed. We have found an approach to this problem that should greatly reduce the cost of the pulsed-power system as compared to alternative systems, such as capacitors, battery banks, or SMES (superconducting magnetic energy storage) systems.

In earlier-reported studies of this problem we have described a system for Maglauncher applications based on extrapolations of a novel high-power generator design that was incorporated in flywheel energy-storage modules developed at the LLNL. These generators employ a special array of permanent magnets (Halbach arrays) on the inner surface of their rotors The field from these arrays induces currents in ironless multi-phase stator windings located inside the arrays and within a vacuum barrier. Owing to the low impedance of the generator and other contributing factors, very high specific powers can be generated. For example, units based on this design, now being manufactured commercially, incorporate a Halbach-array generator having stator windings that are about 10 centimeters in diameter and 20 centimeters in length. This configuration yields an output of 0.35 megawatts from a flywheel rotor spinning at 40,000 RPM and storing approximately $1 \mathrm{kWh}$ (3.6 megajoules). The dimensions and weight of this generator are very small as compared to a conventional generator of comparable power.

For the Maglauncher application the pulsed-power requirements are, of course, much larger than the above figures. For example, to accelerate a rocket and cradle with a combined weight of 50,000 kilograms at a 3-g level, up to a speed of Mach 0.8 (260 meters/sec.), requires, at launch, a pulsed-power level of approximately 400 megawatts. The kinetic energy at launch would be approximately 1.7 gigajoules. Based on an estimated electrical efficiency of the Inductrack drive system between 80 and 90 percent, this amount of kinetic energy would imply the need for about 2.0 gigajoules of electrical stored energy in the pulsed-power system.

In studying this problem in greater depth than the earlier-reported studies we have applied analytical optimization techniques to the problem. In particular, we have considered the following parameters of the system: (1) Thickness of the Halbach array magnets as compared to the thickness of the supporting fiber-composite rotor shell. (2) Pole-order number of the Halbach array. (3) Geometric ratios of the stator windings (determines optimum flux linkage vs winding inductance). Upon performing these optimizations we were able to define the parameters of generators that would best meet the needs of an Inductrack Maglauncher system. As an example of one such case the following table of generator parameters is listed. 


\section{Table I}

Rotor o. d.

Rotor length

Halbach array pole-order number

Peak rotation speed

Stored energy

Peak power output (into matched load)

Estimated materials cost (rotor and gen.)

*(estimated for high-strength carbon fiber and NdFeB magnets)
$1.3 \mathrm{~m}$.

$1.5 \mathrm{~m}$.

32

13,000 RPM

1.0 gigajoule

$200 \mathrm{MW}$

$\$ 40,000^{*}$

If we estimate the cost of the assembled generator at three times the materials cost (possibly an overestimate, considering the high cost per kilogram of the rotor materials) we obtain a figure of $\$ 120,000$ for the unit. To power our Inductrack Maglauncher example one could use two such units, thereby satisfying both the peak power and the energy storage requirements. A more detailed study might suggest the use of a larger number, say four, of somewhat smaller units to optimize the overall system cost. For example, smaller units running at higher rotation speeds typically have higher specific powers, but lower relative stored energy., as compared to larger units. Thus there should exist an optimum compromise between these two trends for a given system, defining the optimal number of units and their power and energy storage parameters.

The cost of the generators is but one element in the overall cost of the pulsedpower system required for a Maglauncher. The other main cost item is the power electronics. Here there may be another substantial cost advantage from employing a Halbach array generator as opposed to dc- or dc-current-based systems such as condenser banks, battery banks, or SMES systems. This potential advantage derives from the following considerations:

The output of the Halbach generator with a high pole-order number consists of multi-phase ac, in our case at kilohertz frequencies. Such an output is almost ideally suited for the use of IGBT (insulated-gate bipolar transistor) solid-state switches employed in a cycloconverter mode. That is, using IGBTs as control elements the multiphase output of the generator can be used directly to synthesize the required waveforms for the Inductrack drive coils, without the need for a dc bus driving an inverter, which then drives the pulse-forming network. Also, the high frequency and multi-phase nature of the generator output will reduce the size of the components (inductors, etc.) needed in shaping the drive pulses. Although these issues need to be further studied, it appears that the Halbach-array generator and its associated power electronics could comprise the 
lowest cost source of pulsed power and energy storage for a full-scale Maglauncher system, not only with respect to initial cost, but also when maintenance and service life issues are considered. 